\title{
Transfer of conceptualization patterns in bilinguals: The construal of motion events in Turkish and German*
}

\author{
MICHAEL H. DALLER \\ University of the West of England, Bristol \\ JEANINE TREFFERS-DALLER \\ University of the West of England, Bristol \\ REYHAN FURMAN \\ Radboud University, Nijmegen
}

(Received: February 3, 2009; final revision received: October 14, 2009; accepted: November 16, 2009; First published online 6 October 2010)

In the present article we provide evidence for the occurrence of transfer of conceptualization patterns in narratives of two German-Turkish bilingual groups. All bilingual participants grew up in Germany, but only one group is still resident in Germany $(n=49)$. The other, the returnees, moved back to Turkey after having lived in Germany for thirteen years $(n=35)$. The study is based on the theoretical framework for conceptual transfer outlined in Jarvis and Pavlenko (2008) and on the typology of satellite-framed and verb-framed languages developed by Talmy (1985, 1991, 2000a, b) and Slobin (1987, 1996, 2003, 2004, 2005, 2006). In the present study we provide evidence for the hypothesis that language structure affects the organization of information structure at the level of the Conceptualizer, and show that bilingual speakers' conceptualization of motion events is influenced by the dominant linguistic environment in both languages (German for the group in Germany and Turkish for the returnees). The returnees follow the Turkish blueprints for the conceptualization of motion, in both Turkish and German event construals, whereas the German-resident bilinguals follow the German blueprints, when speaking German as well as Turkish. We argue that most of the patterns found are the result of transfer of conceptualization patterns from the dominant language of the environment.

Keywords: thinking for speaking, transfer, second language acquisition, motion event construal, Turkish-German bilinguals

\section{Introduction}

The purpose of this article is to show how bilingual speakers' conceptualization of motion events is influenced by the dominant linguistic environment in both languages. In using the term "conceptualization", we follow Levelt (1989), who proposes that speakers first construct a preverbal message in the Conceptualizer and this is subsequently, in the Formulator, mapped onto lexical and grammatical information. In conceptualizing a motion event, the speaker thus first selects the conceptual building blocks, such as the Figure, the Path, the Ground, elements etc. that $\mathrm{s} /$ he wants to use to form propositions (see also von Stutterheim, Nüse \& Murcia-Serra, 2002). The Conceptualizer is assumed to have routine procedures, also sometimes called a set of principles or a blueprint, that guide the decision process involved in organizing information for expression. The output of the Conceptualizer is a preverbal message that specifies, for example, that a Figure moves in a particular Manner along a Path towards a Goal. According to Levelt (1989, p. 145), the Conceptual-

\footnotetext{
* We would like to thank Scott Jarvis for his continuous support and two anonymous reviewers for their comments on earlier versions of this article.
}

izer also has access to information about language-specific requirements, and will thus "know" how the building blocks needs to be packaged in the chosen language.

The fact that conceptualization is based on routine procedures forms the basis for our key hypothesis that bilinguals who are dominant in one language will experience transfer from the dominant language when using the non-dominant language: in other words, bilinguals will rely on routine procedures from the dominant language in constructing, e.g., a motion event in the non-dominant language. From now on we will call these routine procedures CONCEPTUALIZATION PATTERNS. In part, this notion is based on Talmy (1985), who uses the notion LEXICALIZATION PATTERNS to refer to mappings of SEMANTIC structure onto surface elements. However, if we accept Levinson's (1997) position that there is a difference between semantic structure and conceptual structure, and assume the framework outlined by von Stutterheim et al. (2002) and von Stutterheim and Nüse (2003), who give a detailed outline of the processes involved in the conceptualization of motion events, the relevant level of analysis is not semantic structure but conceptual structure. Speakers select the basic building blocks for verbalization at the planning stage of their utterances, that is, at the

Address for correspondence:

Dr Michael Daller, University of the West of England, Faculty of Humanities, Languages and Social Sciences, Frenchay Campus, Coldharbour Lane, Bristol BS16 1QY, UK

Michael.Daller@uwe.ac.uk 
level of the Conceptualizer, and basic elements such as the Figure, Path, etc. are thus represented in some form in the temporary conceptual structure that is the output of the Conceptualizer. We assume that these temporary conceptual structures specify which elements (Path, Manner, etc.) have been chosen for verbalization, and contain some information about the linearization of these basic building blocks, and probably also about how these should be mapped onto linguistic elements (verbs, satellites, etc.) in the chosen language (Levelt, 1989).

The theoretical framework for the analysis of event construals is provided by Talmy (1985 et passim), the Thinking-for-Speaking Hypothesis (Slobin, 1987 et passim) and the Conceptual Transfer Hypothesis (Jarvis, 2007; Jarvis \& Pavlenko, 2008), which will be outlined in section 1.2. On the one hand, we build on previous research on the conceptualization of motion events by focusing on variables that have been analyzed in previous studies, such as the choice of Path verbs versus Manner verbs in boundary-crossing events, and the use of redundant Path satellites among speakers of verb-framed languages. On the other hand, we introduce new elements into the analysis of event construals by focusing on variables that have not yet been taken up in previous studies: namely, how the different components of Path (the Vector, the Conformation and the Deictic) are represented in motion expressions and how bilinguals and monolinguals linearize different units of information (clauses) that have been selected for verbalization.

In the current study we study these variables in narratives produced by two groups of Turkish-German bilinguals who differ from each other in that one group is German-dominant and the other is Turkish-dominant (see section 3.1 for further details on the participants). The study thus aims to contribute to the discussion about the ways in which language dominance at the individual and societal (or cultural) levels affects transfer, an issue raised by Hohenstein, Eisenberg and Naigles (2006) in their study of bidirectional transfer in event construals among early and late bilinguals.

Research on Turkish-German bilingualism is exceptionally suitable for investigating the influence of changes in language dominance patterns on event construals as there are large numbers of Turkish-German bilinguals in different settings due to an intensive work migration from Turkey to Germany in the second half of the twentieth century and a considerable re-migration to Turkey (see Daller, 1999). A further advantage of research into this language pair is the fact that Turkish and German are typologically different languages and therefore meet Lucy's (1992b) suggestion that languages that contrast clearly are good candidates for research into how speakers conceptualize events.

The article is organized as follows. Talmy's classification of motion events is used in section 1.1 to describe typical patterns found in motion events in Turkish and German. In section 1.2, we discuss the notion of transfer, with a specific focus on the Conceptual Transfer Hypothesis and the relation of this hypothesis to the Thinking-for-Speaking Hypothesis. Section 1.3 illustrates conceptual transfer in bilinguals and discusses earlier work in the field. In section 1.4, we briefly discuss the concept of language dominance. In section 2 , we discuss how the present study builds on previous work, what its specific focus is and give some basic information about Turkish word order (2.1). After the sections with the hypotheses (2.2) and the methods section (3) we present the findings of our study (4). We conclude with a general discussion in section 5 .

\section{Theoretical framework of the study}

\subsection{The expression of motion in Turkish and German}

The analysis of the construal of motion events has been a fruitful field of investigation in cross-linguistic studies over the last two decades. Talmy (1985) was the first to analyze the lexicalization of motion events across languages, that is, the systematic association of meaning with particular grammatical elements. A motion event refers to a situation where an entity moves or is located with respect to another entity and it is analyzed as having four internal components: FIGURE, GROUND, PATH and MOTION (see Talmy, 1985, 2000a, b). These can be seen in (1):

(1) The boulder moved down the slope. Figure Motion Path Ground

The Figure is the object that moves or is located. The Motion component refers to the actual presence of motion or locatedness. The Ground is the reference object with regard to which the Figure moves or is located and Path represents the course followed or location occupied by the Figure with regard to the Ground.

Talmy observed that languages differ systematically with respect to the lexical elements that are used to encode information about Path. He suggested that languages can be categorized into two types on the basis of where they characteristically express Path (Talmy, 1985, 2000a, b). Satellite-framed languages (S-languages), such as English and German, typically express Path in a "satellite" of the verb - a member of a grammatical category of constituents other than a noun phrase or a prepositional phrase that is in a sister relation to the verb root. English verb particles such as in, out and across are typical examples of Path satellites. In German, these satellites can be prepositions or the separable part of a separable verb such as hinein-gehen "go into". Verb-framed languages (V-languages), such as Spanish 
and Turkish, on the other hand, typically encode Path in the verb root of the main verb. Examples of Turkish Path verbs are çık- "ascend", in- "descend" and gir- "enter".

For the purpose of this investigation we also need to distinguish between the different components of which Path consists. According to Talmy, the three main components of Path are the Vector, the Conformation and the Deictic. The Vector consists of the basic types of arrival, transversal or departure of the Figure carried out with respect to particular grounds. The Vector component of the Path followed by the Figure consists, for example, of a movement TO a goal or FROM a source, or both. To this fundamental schema, the speaker can choose to add information about the Conformation, i.e., give further details about the geometric complex of which the Ground forms a part. For example, the speaker can choose to add information that the goal is "a point which is of the inside of [an enclosure] = INTO an enclosure" (Talmy, 2000b, p. 53). If the speaker of a V-language wishes to do this, s/he would use a verb that expresses the concept ENTER, whereas a speaker of an S-language would generally choose a Path particle that which expresses this same concept, namely INTO. Apart from this, there is the Deictic component of Path, which relates to the perspective of the speaker. In many languages, there are different verbs for the expression of movement towards the speaker, e.g. come, and movement in a direction other than towards the speaker, such as go.

The difference between the two lexicalization patterns has consequences for the expression of other aspects of the motion event. In addition to the internal components described above, a motion event can also have an external CO-EVENT such as MANNER, that is the specific way the Figure moves, and languages also differ in their characteristic encoding of Manner (Talmy, 1985). Since Path is expressed outside the verb in S-languages "the verb is free to add nuances of MANNER without further elaboration" (Slobin, 2005, p. 312; capital letters in the original). The verb slot can easily be filled with a Manner verb (e.g., run, jump) that conflates Manner and Motion in one lexical item. This option, however, is not available to speakers of V-languages since they tend to express Path through the use of Path verbs. The expression of Manner, then, might be easier for speakers of S-languages than for speakers of V-languages. As Slobin (2003, p. 162) puts it, speakers of S-languages get Manner "for free" whereas speakers of V-languages need much more effort since they need additional lexical items, such as participles, to express Manner in a motion event. In the next section, we outline the differences in the encoding of Manner in Turkish and German.

\section{Manner}

According to Slobin (2003), Turkish is a V-language and German is an S-language. Such a dichotomy is perhaps a simplification and it is probably more appropriate "to rank languages on a cline of Manner salience" (Slobin, 2004, p. 220), but since we deal with only two languages, assuming the existence of a dichotomy is appropriate in the context of this study (for a more detailed discussion see Cadierno, 2008). Özçalışkan and Slobin (2000) analyze Turkish and English narratives and conclude that their analysis of motion verbs provides evidence for a typological dichotomy between the two languages in the encoding of Manner. As English and German are typologically similar in this framework, it can be assumed that these differences also hold for German and Turkish. In German, Manner and Motion tend to be conflated in the main verb, and Path is expressed in a satellite, e.g., hinunter "downwards" in (2), whereas in Vlanguages such as Turkish, either only Path is expressed or Manner is found as an optional element in a subordinate verb, as in (3).

(2) Der Ball roll-te den Hügel hinunter The ball roll-Past the-Acc hill downwards "The ball rolled down the hill."

(3) Top yuvarlan-arak tepe-den aşağ ball roll-Connective hill-Ablative downness in-di descend-Past "The ball descended the hill while rolling." (Allen et al., 2007, p. 17)

There is a clear tendency in V-languages not to express Manner where this aspect of the motion event is not in the foreground. Consequently, V-languages use fewer Manner verbs than S-languages (Slobin, 2003, 2005). But V-languages and S-languages differ not only in the number of Manner verbs that are habitually used but also in where they can or cannot be used. According to Slobin and Hoiting (1994), Manner verbs cannot be used in V-languages where the Path involves crossing a boundary, when the initial location and the final location are in two different spaces. V-languages allow the use of a Manner verb as the main verb in a Path expression only in cases where no boundary crossing takes place (Slobin, 2004, p. 226). According to this boundary crossing constraint, a Manner verb that can be used in German (example (4)) for a boundary crossing would not be licensed in a V-language and the motion event must therefore be expressed with a Path verb in Turkish (example (5)).

(4) Dann will der Vater daraufhin in den Then wants the father therefore in the-Acc Gully steigen

gully climb

"And then the father wants to climb into the gully." (speaker 18, Mono G, Bielefeld, 14 years old) 
(5) Daha sonra baba-s1 in-ip al-1yor Then later father-Poss descend-Ger get-Prog "After that, having descended, his father gets (it)." (speaker 9, Mono T, 20 years old)

The research findings on boundary crossing in Vlanguages are, however, not entirely conclusive. For instance, Naigles, Eisenberg, Kako, Highter and McGraw (1998) found that Spanish speakers use Manner verbs for a motion event where a Figure jumps into a pool. They argue that this might not be a "true boundary crossing" since the Figure performs an "uncontrolled motion" (Naigles et al., 1998, p. 543) after jumping. In the present study, the boundary crossing (climbing into the manhole) is clearly controlled and might yield different verbalizations. In addition, although Spanish and Turkish are both classified as V-languages, there might be differences between them. As mentioned earlier, a simple dichotomy between Slanguages, on the one hand, and V-languages on the other hand, might be a simplification and speakers of Turkish might behave differently from Spanish speakers with respect to boundary crossings.

\section{Path}

There are important differences between the ways in which Path is expressed in Satellite-framed and Verbframed languages. As mentioned earlier, one has to bear in mind that this dichotomy is a simplification, and that minor patterns that differ from the default exist in some languages. Kopecka (2006) has shown, for example, that French, which is normally classified as a Verb-framed language, also shows features that are typically associated with Satellite-framed languages, such as Path expressions with prefixes. However, for the purpose of this article it is important to note that there is a clear tendency for Satellite-framed languages to express more detailed, granular Path descriptions than Verb-framed languages (Slobin, 2005, p. 314). One conduit of this granular Path description is the deictic system. Movement can be expressed with deictic verbs that express a motion towards the speaker (Turkish gel- "come" and German kommen "come"), or a motion in a direction other than towards the speaker (Turkish git- "go" and German gehen "go"). Deictic verbs differ from Path verbs such as enter or arrive in that they do not specify the Vector, i.e., the arrival, traversal or departure that the Figure can execute with respect to a particular Ground (Talmy, 2000b). German has satellites that specify the Vector or the Conformation, and these can be used for fine-grained Path descriptions (see also Bamberg, 1994). The English gloss to the German example shows the quite complicated and unusual construction that would be necessary in English to match the German expression (taken from Slobin, 2005, p. 309).

$\begin{array}{lll}\text { (6) Johann lief } & \text { ins } & \text { Zimmer } \\ \text { John ran } & \text { into the room } \\ \text { Figure Motion+Manner } & \text { Path1 } & \text { Ground/Goal } \\ \text { hin-ein } & & \\ \text { thither.in } & \\ \text { Path2 Path3 } & \end{array}$

In (6), there are three Path satellites, each of which represents a different component of Path. The first, ins "into", refers to movement towards the room, that is the Vector; the second, hin "thither", is a deictic particle that expresses movement away from the speaker, and the third, ein "in", refers to the boundary crossing from the outside world into the room, that is the Conformation. Verbs such as hinein-laufen "walk into" or hinein-rennen "run into" form a subcategory of Manner verbs with a Path satellite, that is quite common in German. Muthmann (1991) lists no fewer than thirty-three examples of rennen "run" + satellite as collocation and eighty examples for laufen "run/walk/go" + satellite. In addition to having a preference for fine-grained Path descriptions, speakers of S-languages can also use more than one Ground element (e.g., Source and Goal) in a clause, which is not common in event construals by speakers of V-languages. According to Aksu-Koç (1994, p. 354) Turkish is similar to other Vlanguages in this regard at this point, in that static locative elaborations are more common than detailed expressions of Path trajectories in clauses with Motion information.

\subsection{Conceptual transfer and thinking-for-speaking}

Before embarking on a discussion of the literature on conceptual transfer, we need to define the concept of transfer itself. As Gass (1996, p. 318) and Jarvis (2000, p. 246) and many others have pointed out, this is difficult, not only because definitions are hardly ever theoryneutral, but also because the notion TRANSFER and many other terms used in bilingualism and related fields are often used in different ways by different researchers (see also Treffers-Daller, 2009). In defining transfer, many researchers refer to second language learners rather than bilinguals. Such definitions are less suitable for the current study, which focuses on bilinguals who have used two languages since early childhood. For the purposes of the current study it is important that the definition of transfer makes reference to bilinguals and to processes (as opposed to products that result from these processes), and covers phenomena that can occur in either language of a bilingual (bidirectional transfer) and can occur in patterns (not just elements in isolation). Although Haugen (1950, p. 230) uses the label "borrowing"1 as the central

\footnotetext{
1 We concur with Heine and Kuteva (2008, p. 59) that the term "borrowing" is best reserved for contact-induced linguistic transfer which involves "phonetic substance, that is, either sounds or
} 
concept, his definition comes closest to what we are looking for: "the process that takes place when bilinguals reproduce a pattern from one language in another." Haugen does not elaborate on the cognitive implications of this process, but he does mention the existence of entrenched habits and points out that "the more habitual and subconscious a feature of language is, the harder it will be to change" (p. 224), which is interesting in relation to Slobin's Thinking-for-Speaking Hypothesis, which will be outlined below. Two important aspects of transfer are, however, not covered in Haugen's definition. First of all, transfer can be a dynamic process. That is, it can lead to the production of spontaneous phenomena resulting from "the involuntary influence of the deactivated language" during online processing (Grosjean, 2008, p. 38). In other words, the phenomena need not (yet) be incorporated into the system of the recipient language. Second, according to Mougeon, Nadasdi and Rehner (2005, p. 103), transfer may be overt or covert. OVERT INTER-SYSTEMIC TRANSFER represents a QUALITATIVE development in one of the languages in a bilingual setting, such as the relaxing of a syntactic rule, whereas COVERT INTERSYSTEMIC TRANSFER refers to a QUANTITATIVE development, namely a marked increase in the frequency of a feature at the expense of an alternative feature (or alternative features).

Linguistic transfer (also called cross-linguistic influence) affects all linguistic subsystems (Odlin, 2005), including semantics. ${ }^{2}$ We assume with Levinson (1997) that semantic representations are distinct from conceptual representations (but see Cadierno (2008) for a different opinion). If this is indeed the case, it is important to clarify the difference between semantic transfer and conceptual transfer, prior to reviewing the available evidence with respect to the existence of transfer involving conceptualization patterns.

Semantic transfer involves the link between words and concepts but not the make-up of the concepts themselves (Jarvis, 2007). The following example of semantic transfer in an utterance produced by a Finnish learner of English is helpful to illustrate the difference between semantic and conceptual transfer: "he bit himself in the language" (Ringbom, 2001, p. 64). The speaker's intention was to say "in the tongue" but Finnish has only a single word for "language" and "tongue", which caused this incidence

form-meaning units such as morphemes, words, or larger entities". This is not the case in our study, which focuses on concepts and meanings and the structure or patterns in which they occur. For this form of transfer, Heine and Kuteva use the term "replication".

2 We are grateful to one of the reviewers for pointing out that the phenomena under investigation could potentially be seen as convergence. Space does not allow us to discuss the similarities and differences between contact phenomena in this article, but a discussion of the similarities and differences between code-switching, transfer and convergence can be found in Treffers-Daller (2009). of semantic transfer. In this case the speaker's L1 has exerted influence on his/her L2, but there is no indication that transfer has taken place at a conceptual level, since "conceptual knowledge involves extralinguistic mental representations" (Jarvis \& Pavlenko, 2008, p. 73) and it is obvious that the speaker knows the difference between "language" and "tongue" at a conceptual level. When, however, Russian learners of English refer to paper cups as glasses, this is arguably a case of conceptual transfer, because English and Russian differ in the categorization of objects as "glasses" or "cups" and the learner uses an L1 concept in an L2 context (see Jarvis \& Pavlenko (2008) for further details). The information provided about this example does not allow us to establish, however, whether the speaker's inventory of mental concepts has been affected or whether the conceptual transfer occurred during the online processing of those concepts. As Jarvis (2007) points out, it is important to distinguish between CONCEPT TRANSFER and CONCEPTUALIZATION TRANSFER. The first of these two refers to transfer that arises from cross-linguistic differences in the conceptual categories stored in L2 users' long-term memory, whereas conceptualization transfer arises from cross-linguistic differences in the ways L2 users process conceptual knowledge and form temporary representations in their working memory.

Evidence for the existence of both kinds of conceptual transfer has led to the formulation of the Conceptual Transfer Hypothesis (Jarvis, 2007), according to which a person's patterns of language use in one language can reflect the concepts and patterns of conceptualization that the person has acquired as a speaker of another language. This hypothesis is closely related to Slobin's (1987) Thinking-for-Speaking Hypothesis (but see Jarvis (2007) for a discussion of similarities and differences). In Slobin's framework, language specificity is not to be found in the mental images that individuals have in their conceptual stores (which would be a case of concept transfer when it involves cross-linguistic effects), but it is found with respect to which (elements) of those images are selected for verbalization - a phenomenon whose cross-linguistic effects are referred to as conceptualization transfer in Jarvis's terminology. Thinking for speaking involves "picking those characteristics that (a) fit some conceptualisation of the event and (b) are readily encodable in the language" (Slobin, 1987, p. 435). As events cannot be directly encoded in language, speakers or writers need to verbalize a particular aspect of motion event, that is, "experiences are filtered through language into verbalised events" (Slobin, 1996, p. 75; emphasis in original). Children become used to paying attention to particular aspects of motion events and to particular ways of verbalizing these from a very young age, as Aksu-Koç (1994) and Allen et al. (2007) have shown for the L1 acquisition of Turkish. From a cognitive linguistic point 
of view, this is important because the training children receive in the verbalization of Motion may lead to these verbalizations becoming cognitively entrenched in that they are well-rehearsed and automatic routines that are easily elicited and reliably executed (Langacker, 2000, p. 3). Slobin (1996, p. 89) claims that there are important consequences for second language learning: if the training one receives in childhood is "exceptionally resistant to restructuring in adult second-language acquisition", it is likely that the patterns learnt in early childhood are transferred to a second language.

In their studies of the cognitive processing of motion events, von Stutterheim et al. (2002) and von Stutterheim and Nüse (2003) provide evidence for the hypothesis that in the construal of events, speakers do indeed access extralinguistic mental representations (and not only linguistic forms). Their work shows that there are systematic differences between speakers of different languages in the ways in which they plan the production of utterances, that is, in the information they select for verbalization, in the segmentation, structuring and linearization of that information and in the perspectives they take on the event. Crucially, all the tasks involved in the construal of an event have to be carried out in the Conceptualizer (Levelt, 1989), prior to the retrieval of linguistic forms. Thus, the principles or strategies (or blueprints) used by speakers to construe events are deeply rooted in the planning stages of verbal processing.

An important question that remains to be answered is then at what level of processing transfer takes place. Levelt (1989) suggests that the construction of the preverbal message in the Conceptualizer involves two steps: macro-planning and micro-planning. In macroplanning, the speaker elaborates the communicative intention as a sequence of subgoals and selects the information that is to be represented in speech. Microplanning is concerned with the further shaping of the message to bring it into the format required by the preverbal message. The product of conceptualizing is the preverbal message, which is then passed on to the Formulator for grammatical and phonological encoding. According to Levelt (1989, p. 145), one aspect of microplanning is the acknowledgement of the Formulator's language-specific requirements. In the course of language acquisition, children learn what kinds of distinctions are relevant for their mother tongue(s); for example, whether a language has aspect or not. For adults, the languagespecific requirements on semantic structure are part of the Conceptualizer's procedural knowledge base (p. 105). The speaker is assumed to have a set of routine procedures that acknowledges automatically whatever the language requires (p. 157).

Some evidence regarding the planning of multi-clause utterances can be obtained from studies on fluency. Pawley and Syder (2000, p. 195) suggest that "competent speakers are able routinely to plan in advance the core (or obligatory) grammatical phrases of simple clauses and of certain kinds of complex clauses". As is well known, speakers do not create all utterances from scratch. Instead, speakers rely on a stock of familiar multi-clause syntactic frames that are memorized independently of lexical content (p. 195).

The notion of routine procedures or blueprints is related to the concept of thinking-for-speaking. We assume that these blueprints are cognitively entrenched, which makes it difficult to learn a new way of thinking-for-speaking, and that L2 learners use L1 blueprints in building structures in L2. Support for this position comes from Caroll and von Stutterheim (2003, p. 398), who show that even advanced L2 learners "remain rooted in at least some of the principles of conceptual organisation as constituted in the course of L1 acquisition".

It remains controversial, however, to what extent language influences conceptualization. Levinson (1997, p. 22) assumes that the acquired habits of language production result in speakers of typologically different languages entertaining systematically different thoughts, for example, in the domain of spatial relations. Thus, in his view, the influence of language on concept formation goes much further than the levels of macro- or microplanning, and extends to general cognition. This would also be the position of neo-relativists, who argue that cognition in general is influenced by language-specific categories (see Lucy (1992a, b) or Danziger (2001) for a fuller discussion).

Von Stutterheim and Nüse (2003), on the other hand, do not think that cognition in general is languagedependent, but argue that language influences microplanning and macro-planning. They elaborate on Levelt's model by assuming that the planning of utterances involves four stages - segmentation, selection, structuring and linearization - and present evidence that there are systematic differences between speakers of English and German in the ways they organize information under different perspectives. We hope to provide some evidence that there are systematic differences between bilingual groups in the ways in which they select and linearize units of information, and that these differences relate to their language dominance patterns. To our knowledge, the issue of linearization has not yet been taken up in studies of conceptual transfer (apart from Caroll and von Stutterheim's (2003) study on perspective taking) and therefore this contribution is one of the first in this area.

Evidence for conceptual transfer in second language learners can be found in various studies. Inagaki (2001), for example, found that Anglophone learners of Japanese accept English-like manner of Motion verbs preceded by directional PPs in Japanese, although these are rejected by Japanese control groups. Cadierno and Ruiz (2006) also found some evidence for conceptual transfer in 
L2 expressions of motion events: their Danish learners of Spanish incorporated more ground specifications in Spanish clauses than Spanish native speaker groups, and they also produced constructions that involved a violation of the boundary crossing constraint. In their study of oral narratives of British learners of French and French learners of British English, Treffers-Daller and Tidball (in prep.) found evidence for the transfer of $\mathrm{L} 1$ conceptualization patterns, including violations of the boundary crossing constraint even among advanced learners of French. There is therefore some evidence that it is difficult to restructure conceptualization of Motion in the process of L2 learning. According to Cadierno (2008, p. 265), however, advanced learners are able to retrain their thinking-for-speaking patterns to a large extent when talking about Motion in an L2 that is typologically different from their L1, although in some areas (e.g., gestures) traces of L1-based patterns are still detectable in these learners.

\subsection{Conceptualization of motion events in bilinguals}

Most studies in this area of research deal either with the development of conceptualization patterns in the first language or with the transfer of L1 patterns in L2 acquisition. There are only a few studies that deal with the development of conceptualization patterns in bilinguals who grow up with two languages simultaneously and are exposed to conflicting patterns in their two languages from birth. Bidirectional cross-linguistic transfer can be assumed in these cases, but we know little about the factors that influence this type of transfer. Slobin $(2005$, p. 318$)$ claims that the two languages of a bilingual trigger different conceptualization patterns in that "bilinguals tested in both languages systematically report more mental imagery for Manner of motion, and less for physical surroundings, when reading in English, in comparison with Spanish". One of the characteristics that sets conceptual transfer apart from the types of transfer that are more purely linguistic in nature (e.g., phonological, syntactic, semantic transfer) is that conceptual transfer appears to be more inherently bidirectional and convergent (see Jarvis \& Pavlenko, 2008). That is, studies that investigate cross-linguistic influence in learners' and bilinguals' patterns of conceptual categorization and event construal often find that the participants show simultaneous influences from both languages in a single domain, with the result that the way they express motion events, for example, falls somewhere between the patterns found among monolingual speakers of the two languages. This finding emerges in several of the articles in this issue, as well as in several previous studies, including, but not limited to, several studies discussed in Jarvis and Pavlenko (2008).
In one such study that focused on bidirectional transfer in the conceptualization, or construal, of motion events, Hohenstein et al. (2006) compare the use of Manner and Motion verbs by Spanish-English bilingual and monolingual groups. The bilinguals in this study had all learned Spanish first and then either started learning English at the age of 5 or below (early group) or after the age of 12 (late group). ${ }^{3}$ The authors show that Spanish monolinguals used more Path than Manner verbs to describe motion events presented in videos, whereas English monolinguals used many more Manner verbs than Path verbs for the same events. This is in line with expectations, as Spanish is classified as a V-language and English as an S-language. Spanish-English bilinguals, however, have a tendency to comply with the languagespecific patterns when speaking either Spanish or English, but they take the middle position overall. Thus, their Spanish descriptions include fewer Manner verbs than their English ones, but still more compared to the Spanish descriptions of the monolinguals. On the other hand, their English descriptions contain more Manner verbs than their Spanish ones, but still fewer than the description of the monolingual English speakers. Hohenstein et al. (2006, p. 258) report that they found bidirectional transfer specifically among late bilinguals and not among early bilinguals. This is a clear indication that bidirectional transfer takes place in principle, but that it is influenced by factors such as the age of onset of second language learning. They also indicate that language dominance may play a role in transfer, and point out there is the need to study the differential effects of language dominance.

The acquisition of language-specific conceptualization patterns seems to start from a very early age. Hickmann and Hendriks (2006) show that three-year-old monolingual children follow the specific patterns of their first language in their description of spatial relations, and Choi and Bowerman (1991) find evidence that bilingual children are sensitive to the routinized patterns of their two languages from as early as $17-20$ months. This is important for the current study, because bilinguals who have grown up with two languages will have become sensitive to the routinized patterns of two (or more) languages from a very early age. This makes the construal of motion events by bilinguals a promising research area for research into the transfer of conceptualization patterns.

Studies on bilinguals in language contact settings can give us more insight into how bilinguals in these settings react to the preferences of their different languages. Of special interest are contact situations between S-languages and V-languages. According to Kramer (1981) and Slobin

3 It is beyond the scope of this article to discuss whether the early group should be regarded as bilinguals and the late group as second language learners or late bilinguals. In our description we follow the labels used by Hohenstein et al. 
(2004), in many Romance-Germanic contact situations along the geographical border between these languages, Path particles are incorporated by bilinguals into their use of the Romance languages and used in combination with path or manner verbs. Some evidence for this was found in frog stories collected among French-Dutch bilinguals, who used a redundant Path particle en bas "downwards" in combination with the Path verb tomber "fall" (TreffersDaller, in press b) as in (7), or a Manner verb courir "run" in combination with a prepositional phrase dans les bois "into the woods" as in (8), which expresses attainment at a final location. This is not allowed in standard French because of the boundary crossing constraint. ${ }^{4}$

(7) allez et en une fois y a un hibou

Well and suddenly there is an owl

qui sort

which comes.out

et il se saisit tellement qu' il

and it itself shocked so much that it

tombe en bas

falls down

"Well and suddenly there is an owl which comes out and he is so shocked that he falls down."

(corpus Treffers-Daller, speaker 19)

(8) Le cerf s' en va et court dans

The deer Refl there goes and runs into

les bois

the woods

"The deer goes away and runs into the woods."

(corpus Treffers-Daller, speaker 27)

Not all uses of redundant directional adverbs can be explained as resulting from transfer, however. Sebastián and Slobin (1994, p. 264) report that redundant directional adverbs can be found among preschool Spanish children (9). They also report that children used directional adverbs that were not redundant but more elaborate than one would typically find among older speakers.

(9) Entonces abajo se cayó

"And downwards (he) fell."

[s4e, 4;6] (Sebastián \& Slobin, 1994, p. 264)

Sebastián and Slobin assume that children may feel the need to reinforce the directional meaning already expressed in the verb, and suggest there may be a Ushaped development pattern here, as the phenomenon is less common with the youngest group and with older speakers.

${ }^{4}$ It is not possible to establish with certainty that the picture represents a boundary crossing as the deer may well be at the boundary of the woods. The speaker does, however, first mention the fact that the deer is going away (le cerf s'en va), which seems to suggest that he is not currently in the woods. If this interpretation is correct, the deer does indeed cross a boundary into the woods.
Cadierno and Ruiz (2006, p. 204) found similar uses of redundant and anomalous Path particles in Spanish as spoken by Danish learners (10-11).

\section{(10) La colmena cayó abajo \\ "The beehive fell down." \\ (11) El perro salío afuera \\ "The dog went outside."}

Further examples of conceptual transfer in the domain of Motion can be found in the work of Helms-Park (2001, 2003), and Odlin (2008) provides a detailed overview of further studies in the field. The available evidence suggests that conceptualization patterns are indeed transferable. If this is the case, this constitutes important evidence for Jarvis's (2007) Conceptual Transfer Hypothesis.

\subsection{Language dominance}

As the current study aims to contribute to the discussion about the ways in which language dominance affects transfer, it is important to briefly outline our view of language dominance here first (but see Daller, Yıldız, De Jong, Kan and Başbağı (in press) and Treffers-Daller (in press a) for a fuller discussion). Hamers and Blanc (2000, p. 9) consider language dominance to be one of the psychological dimensions of bilingual ability (or in their terminology "bilinguality") in individuals. Under this view, language dominance refers to the relationship between the competencies in the two languages of the bilingual. A distinction is often made between balanced bilinguals, who have equivalent competence in both languages, and dominant bilinguals, whose competence in one language is more developed than that in the other (p. 8). Many researchers point out that completely balanced bilinguals are very rare. It is much more common for bilinguals to be dominant in one or the other language (Baker \& Jones, 1998, p. 12). To Grosjean (2008, p. 24), language dominance is a reflection of the complementarity principle, i.e., the fact that bilinguals use their two languages for different purposes (or different domains) in daily life.

Language dominance is, however, a factor not only at the micro-level of the students' individual language proficiency profiles, but also at the macro-level of society. Hohenstein et al. (2006, p. 259) recognize this when they note that these two different kinds of language dominance may affect transfer, and they call for research in which bilinguals using the same two languages are studied in different environments, so that the differential role of both forms of language dominance may be evaluated.

We take the view that language dominance at a societal level is reflected in the individual. We use the term "reflection" on purpose because we assume that the changes in a bilingual's environment trigger the changes 
in his/her language dominance (not vice versa). Therefore, we consider societal or cultural language dominance to be the key factor behind language dominance at the individual level. Although we cannot separate these two aspects of dominance in a clear-cut way, it seems important to point out that if the language environment changes, e.g., in the current study through the return to Turkey of one group of participants, it is most likely that the individual dominance patterns will also change eventually. Support for this position comes from Grosjean (1998, p. 132), who explains that "the language repertoire of bilinguals may change over time: as the environment changes and the needs for particular language skills also change, so will their competence in their language." It is exactly this change in the environment that distinguishes the two bilingual groups in the present study.

\section{The present study}

The aim of the present study is to investigate to what extent bilingual speakers' conceptualization of motion events in both languages is influenced by the dominant linguistic environment in which they live. The present study fills a gap in our knowledge about conceptual transfer in a number of ways. First of all, much less is known about conceptual transfer in bilinguals than in L2 learners, in particular in relation to the expression of Motion. The participants in the current study are not L2 learners because they grew up using both languages from a very early age. Second, the methodology proposed for this study is novel in that different groups of bilinguals are not only compared with monolinguals of each language, but also with each other. While most studies are limited to a comparison of bilinguals/L2 learners and monolinguals, with some studies including learner groups with different L1 backgrounds (see Jarvis, 2000), no other study has compared motion expressions in bilingual groups who share the same language pair but live in different countries and are therefore exposed to environments in which a different language is dominant. The key difference between these groups of bilinguals is that the environment in which they live is German-dominant for one group (the bilinguals in Germany) but Turkish for the other group (the bilingual returnees). This study can thus contribute to our understanding of the role of language dominance in transfer (Hohenstein et al., 2006). Third, while we focus on various variables that have been studied before (such as choice of Path verbs versus Manner verbs, and the use of redundant Path satellites in V-languages), we have added two new elements into the discussion, namely a detailed analysis of the Conformation component of Path (see section "Path" for details) and a focus on the linearization of information units (clauses), that have not been discussed before in the literature on motion event construal.
No studies have so far addressed the possibility that the planning of the linear order of clauses in a sentence might also be subject to transfer. In the current study we hope to provide evidence for the fact that the linear order of clauses that express Goal-Action or ActionGoal sequences produced by bilinguals in Germany differs significantly from that of bilinguals living in Turkey. We assume that it is the entrenchment of the multiclause frame that is used in the dominant language of the environment (German) that leads to transfer, i.e., results in the preference of bilinguals who have always lived in Germany to use this as their default syntactic frame in the planning of Turkish utterances containing Action-Goal sequences (see section 2.1 for a descriptive overview of these structures).

In the current study we approach the issue by studying three kinds of evidence that constitute indicators for transfer, following the methods proposed by Jarvis (2000) and Jarvis and Pavlenko (2008). As their indicators were formulated for learners rather than bilinguals, we have adapted them somewhat so that they are applicable to the current study. Instead of comparing different groups of learners who are acquiring a second language, we compare different groups of bilinguals who share the same two languages, but use these in different environments. We will refer to the language from which the transfer effects originate as the SOURCE LANGUAGE, and the language in which the transfer effects are found as the RECIPIENT LANGUAGE.

The criteria used are as follows:

(a) intragroup homogeneity: each group of bilinguals should display a level of uniformity in their use of the recipient language;

(b) intergroup heterogeneity: there should be clear differences between each group of bilinguals and/or between the bilinguals and monolinguals in their use of the recipient language;

(c) cross-linguistic performance congruity: the patterns found in the source and the recipient language should be qualitatively congruent.

In Jarvis and Pavlenko (2008) this refers to congruity between the performance of speakers in the source and the recipient language. Cross-linguistic performance congruity is interpreted in a slightly different way in this study. Because the students told one story in German, and another one in Turkish, we cannot compare the performance of bilinguals in both languages with respect to the same motion event. Instead, we will use the term "cross-linguistic performance congruity" to refer to congruity between the patterns found in the performance of monolingual speakers of German (source language) and the performance of bilinguals in Germany using Turkish (recipient language) or between patterns found in the 
performance of monolingual speakers of Turkish (source language) and the performance of returnees using German (recipient language).

\subsection{Basic word order in Turkish}

According to Göksel and Kerslake (2005), the unmarked word order for major constituents in Turkish sentences is Subject (Object) Verb (SOV). Thus, the predicate appears at the end of a sentence. In standard Turkish, nominalized subordinate clauses (including postpositional clauses) normally precede the predicate in the main clause (Kornfilt, 1997, p. 46). This is also the case with postpositional clauses containing the postposition için "to, for", that express the goal or the reason of an action, as exemplified in (12), where the postpositional clause (topu almak için "to fetch the ball") precedes the main clause, which expresses the action itself (babast iniyor "his father descends"). The postpositional clause is bracketed in the example to clarify the underlying structure. Alternative word orders, such as the one in (13), where the postpositional clause is extraposed to the right side of the main verb, are possible depending on considerations of topic, focus, etc. (Kornfilt, 1997, p. 91).

(12) [Top-u al-mak için] baba-sı iniyor Ball-Acc fetch-Nom to father-Poss descend-Prog "To fetch the ball, his father descends."

(13) Baba-s1 in-iyor [top-u almak için] father-Poss descend-Prog ball-Acc fetch-Nom to "His father descends to fetch the ball."

For the purposes of the current investigation, it is important to note that the unmarked word order is the one given in (12) (see Kornfilt, 1997; Göksel \& Kerslake, 2005).

In German, on the contrary, the unmarked order of these constituents is different. The most common way to express an Action-Goal sequence is as given in (14).

(14) Der Vater steigt in den Gully [um den Ball zu holen]. "The father climbs into the manhole [to fetch the ball]."

The alternative order, given in (15), is possible but considered as marked (see Schoenthal, 1993).

(15) [Um den Ball zu holen] steigt der Vater in den Gully. "[To fetch the ball] the father climbs into the manhole."

An alternative way of looking at these constructions would be to consider them as examples of syntactic transfer. It is possible to hypothesize that VO structures have increased more generally in immigrant Turkish in Germany, and that this increase is due to the influence of German. If this were the case, we would expect to see a wide range of constituents in postverbal position, and not only Goal PPs. To the best of our knowledge, there is no evidence for this hypothesis so far, even though, according to Johanson (2002), constant copying from Slavic and Romanian into the Turkic languages spoken in the Balkan area has resulted in word order changes in Gagauz and Karaim to such an extent that complements and free adverbials generally follow the predicate. Doğruöz and Backus (2009) did not find much evidence for the increase of VO structures in Turkish as spoken in the Netherlands, although in a follow-up study, Doğruöz and Backus (2009) discuss evidence for other patterns that native speakers of Turkish as spoken in Turkey would classify as "unconventional", many of which could be the result of Dutch influence. Whether evidence for an increase in OV patterns can be found in Turkish as spoken in Germany is a very interesting question, but it is clearly beyond the scope of this article.

\subsection{Hypotheses}

The key hypotheses of the current study are that both groups of bilinguals will display bidirectional transfer in the conceptualization of motion events and that the balance of influence from each language can be predicted by the dominant linguistic environment in which the groups live. Since our data are based on two different picture stories (see section 3, "Method") we need to have different hypotheses for the two languages, but they all focus on bidirectional transfer. Based on the theoretical assumptions we discussed so far we predict the following for the construal of motion events IN TURKISH:

(i) Bilinguals in Germany will describe Path in Turkish in ways that are more typical for German, in that they will choose to

(a) select the Conformation component (ENTER) of Path, which is atypical for monolingual Turkish speakers.

(b) use more redundant Path satellites than returnees and monolinguals in Turkey.

(ii) Bilinguals in Germany will choose to linearize the different components of Event 1 as an ACTION-GOAL sequence, which is typical for the German patterns for organizing information in clauses, whereas returnees will be closer to the Turkish monolingual patterns for the linearization of motion events in that they prefer GOAL-ACTION sequences.

(iii) A subgroup of bilinguals who live in Germany but had had more contact with Turkish at the time of recording (due to their specific migration background) will experience less influence from 
German in their conceptualization of events in Turkish.

(iv) The differences between the bilinguals and the monolinguals cannot be explained as resulting from incomplete acquisition of the typical patterns in which events are construed in Turkish; therefore all groups will avoid Manner verbs in boundary crossings in Turkish.

For the construal of motion events IN GERMAN we predict that:

(i) The returnees will use fewer Manner verbs than the bilinguals in Germany for the description of motion events with a boundary crossing in German, because the returnees experience transfer from routinized patterns involving boundary crossings in Turkish, which does not license the use of Manner verbs in such constructions.

(ii) The bilinguals in Germany will use more Manner verbs in this context than the returnees, and thus will be closer to the routinized patterns of monolingual German speakers.

\section{Method}

\subsection{Participants}

The subjects of the present study were two groups of bilinguals and two groups of monolinguals.

The first group were forty-nine bilingual students ("B stud") who grew up in Germany or went there at a very young age. This group consists of twenty university students (mean age 21.1, age range 18-26, SD 2.58) and twenty-nine secondary school students (mean age 14.9 , age range 13-19, SD 1.40). The bilingual students from group 1 were all in the German educational system and had a clear expectation to finish their school or university there and to stay in Germany. All of them had a Turkish immigration background. Whereas sixteen of the university students were born in Germany or went there at a very young age (below the age of three), five came to Germany at the age of fourteen or above. A frequently used cut-off point between early and late bilinguals is the age of three (McLaughlin, 1978; Meisel, 2000). According to this classification, the five university students who came to Germany after the age of fourteen are clearly late bilinguals. We have no information about when the other students started to learn German, but the fact that in a number of surveys (see Daller, 1999) bilinguals in Germany regularly say that they speak German and Turkish equally with their siblings is an indication that German plays an important role in their bilingual first language acquisition from a very early age. We therefore assume that the majority of the participants in group 1 (apart from the five who came to Germany after the age of fourteen) can be classified as early bilinguals. However, three of these early bilinguals had had additional exposure to Turkish at the time of recording as they went back to Turkey for several years and attended schools there before they finally came back to Germany. There are thus eight participants in the bilingual group who live in Germany who have a language background that is different from the rest of this group.

The second group of bilinguals were thirty-five students ("B return" from Bursa; mean age 20.8, age range 7-26, SD 2.48) who were either born in Germany or had arrived there at a very young age but returned to Turkey at an average age of 13.3 (age range 10-16, SD 1.54) to finish their secondary school and start a university education. These returnees had been back in Turkey for more than seven years at the time of data collection. Their career expectations clearly lie in Turkey (see Daller \& Grotjahn (1999) and Daller, van Hout \& Treffers-Daller (2003) for a detailed description of this group).

As the German control group, we had students from two different secondary schools in Germany. One subgroup ("Mono Ger 1" from Bielefeld; $n=30$, mean age 13.7, age range 13-15, $S D 0.56$ ) told the first narrative (Event 1/the Ball story - see Appendix 1); the other subgroup ("Mono Ger 2" from Heilbronn; $n=23$, mean age 15.65, age range 13-20, $S D 1.921$ ) related the second narrative (Event 2/the Bank story - see Appendix 2). It was necessary to use two different subgroups for the two narratives because the recordings took place at schools, and due to time restrictions each group could only tell one of the picture stories (see Table 1). We used a questionnaire about the educational and social background of the monolingual group to make sure that their background is comparable with the bilingual groups.

The group of sixty-eight monolingual Turkish speakers ("Mono T" from Istanbul) included forty secondary school students (mean age 13.2, age range 12-14, SD $0.6)$ and twenty-eight university students from Marmara University in Istanbul (mean age 20.7, age range 19-24, $S D$ 1.02).

All bilinguals except the five in the "B stud group" who arrived in Germany after the age of fourteen are early bilinguals. As they have used both languages in daily life from early childhood onwards, we prefer not to classify Turkish and German as the students' L1 and L2 respectively. For our participants, the relative dominance of the languages in the individual is much more important than the question of which language was acquired first. As we have shown in earlier studies (Daller, 1999; Daller \& Grotjahn, 1999; Daller, van Hout \& Treffers-Daller, 2003; Treffers-Daller, Özsoy \& van Hout, 2007), there are significant differences between the language dominance profiles of the bilingual students in Germany and the returnees. Although both groups are clearly bilingual in 
Table 1. Narratives by group.

\begin{tabular}{lllll}
\hline \hline & $\begin{array}{l}\text { Event 1/Ball } \\
\text { story in Turkish } \\
\text { (Appendix 1) }\end{array}$ & $\begin{array}{l}\text { Event 1/Ball } \\
\text { story in German } \\
\text { (Appendix 1) }\end{array}$ & $\begin{array}{l}\text { Event 2/Bank } \\
\text { story in Turkish } \\
\text { (Appendix 2) }\end{array}$ & $\begin{array}{l}\text { Event 2/Bank } \\
\text { story in German } \\
\text { (Appendix 2) }\end{array}$ \\
\hline $\begin{array}{l}\text { Bilinguals in Germany } \\
\text { Bilingual returnees }\end{array}$ & $\mathrm{x}$ & $\mathrm{x}$ & $\mathrm{x}$ \\
$\begin{array}{l}\text { Monolingual subgroup German 1 (Bielefeld) } \\
\text { Monolingual subgroup German 2 (Heilbronn) }\end{array}$ & $\mathrm{x}$ & $\mathrm{x}$ & $\mathrm{x}$ \\
Monolingual Turks & $\mathrm{x}$ & $\mathrm{x}$ & $\mathrm{x}$ \\
\hline \hline
\end{tabular}

the sense that they use Turkish and German on a daily basis, they use these languages for different purposes and in different domains of life (Grosjean, 1997). An important factor here is the language of the school, which is German in Germany, with hardly any supplementary lessons in Turkish (see also Daller, 2005). German is also used in almost all public domains in Germany, so that at the wider, societal level, German is also the dominant language. On the basis of our knowledge of the students' use of the two languages and the information about the role of German in German society at large, we assume that the bilinguals in Germany are German-dominant. As for the returnees, they still use German in some private domains, e.g., in communication with siblings (see Daller, 1999, 2005), but the language they use in all public domains is Turkish (apart from some school lessons). As a result, we assume that the bilinguals in Turkey are Turkishdominant.

Evidence for our claims regarding the relative dominance of each language at the level of the individual was obtained from previous studies of the same informants, in which we studied the lexical richness of the descriptions in Turkish and German of the same stories as in the present study (Daller et al., 2003). ${ }^{5}$ This study shows that, in line with expectations, the bilinguals in Germany have higher scores for lexical richness in German and lower for Turkish when compared with the returnees. At the level of syntax, we analyzed the students' use of complex embeddings in Turkish (Treffers-Daller et al., 2007), and showed that the bilinguals in Germany use fewer and less complex syntactic embeddings than the returnees or the monolingual Turks.

5 In Daller et al. (2003) we studied the same university students (B stud) and returnees (B return), and in Treffers-Daller et al. (2007) we studied these same groups, as well as the monolingual control group (Mono T) from Marmara University. For the current study, data from monolingual students from secondary schools in Bielefeld (Germany) and bilingual students from secondary schools in Heilbronn (Germany) were added, as well as data from monolingual students from secondary schools in Istanbul.

\subsection{Procedure and materials}

The elicitation materials used were the so-called fatherand-son stories (Plauen, 1996 [1952]), which were also employed in our previous studies on the language proficiency of the different groups mentioned above. The participants were asked individually to tell two short picture stories aloud. In order to avoid translation effects, the bilingual participants were asked to tell one story in Turkish and another story in German. The data collection was carried out in the schools or universities of the participants by monolingual research assistants for the monolingual groups and by bilingual assistants for the bilingual groups. The narratives collected are shown in Table 1.

\subsection{Data analysis}

The stories were audio-recorded, transcribed into CHAT format (MacWhinney, 2000a, b) and analyzed with the help of CLAN tools. The analysis of the data in the present article focuses only on two motion events in these two picture stories with a clear boundary crossing (see discussion below). The present study therefore differs from earlier studies (e.g., Hohenstein et al., 2006; Naigles et al., 1998) in the sense that instead of using a variety of stimuli with relatively small samples, we used only two picture stories with a variety of bilingual speakers. The focus of the present study is therefore not so much on typological contrasts between the languages in question but on the way the different groups of bilinguals construe the same event, and to what extent these event construals correspond to those most commonly found among monolingual speakers of each language.

We decided to focus on the construal of two events in the father-and-son stories. The first event revolves around a man (the father) who goes down a manhole to fetch a football, and the second event concerns a burglar who runs into a bank. These scenes were selected because speakers of Turkish and German are likely to construe the events depicted here differently, because they both involve a boundary crossing. As explained in sections 1 and 2, we can expect differences in the construal of the event 
Table 2. Classification of expressions used by the participants for the Event 1/Ball story.

\begin{tabular}{|c|c|c|c|}
\hline Conformation & Vector & Turkish & German \\
\hline \multirow[t]{2}{*}{$\begin{array}{l}\text { Path without Conformation } \\
\text { (-ENTER) }\end{array}$} & $\begin{array}{l}\text { Neutral movement } \\
\quad(\text { deictic })\end{array}$ & git- "go" & gehen "go" \\
\hline & $\begin{array}{l}\text { Vertical movement } \\
\text { (downwards) }\end{array}$ & in- "descend" & runtergehen "go down" \\
\hline $\begin{array}{l}\text { Path with Conformation } \\
\text { (+ENTER) }\end{array}$ & & gir- "enter" & reingehen "go into" \\
\hline \multirow[t]{2}{*}{$\begin{array}{l}\text { Manner + Path conflation without } \\
\text { Conformation ( }- \text { ENTER) }\end{array}$} & $\begin{array}{l}\text { Vertical movement } \\
\text { (downwards) }\end{array}$ & n.a. & $\begin{array}{l}\text { hinunterklettern/ runterklettern "climb } \\
\text { down" hinuntersteigen "climb/step } \\
\text { down" }\end{array}$ \\
\hline & Not vertical & n.a. & $\begin{array}{l}\text { hinterher klettern/ hinterher steigen } \\
\text { "climb/step after" }\end{array}$ \\
\hline $\begin{array}{l}\text { Manner }+ \text { Path conflation with } \\
\text { Conformation }(+ \text { ENTER) }\end{array}$ & & n.a. & reinklettern/ reinsteigen "climb/step into" \\
\hline
\end{tabular}

to surface in the expression of Manner as well as Path of motion. Although Slobin's (2004) statement that the expression of Path is obligatory may need to be qualified, ${ }^{6}$ the Path followed by the Figure in these scenes is key to the development of the stories and very clearly depicted. Therefore we assumed that most speakers would choose to relate this part of the story in sufficient detail.

The variables that we decided to analyze (the Conformation component of Path; the use of redundant Path satellites; the linearization of clauses; and the choice of Manner and Path verbs in boundary crossings) were chosen because monolingual speakers of each language perceive some of the lexical choices or constructions produced by the bilinguals as unconventional ${ }^{7}$ and potentially induced by the language of the environment where the bilinguals are living (see also Doğruöz \& Backus, 2009). All measures that we use are based on dichotomous variables: descriptions with or without a Conformation component; descriptions with a redundant Path satellite versus descriptions without one; descriptions that contain an Action-Goal linearization versus descriptions with a Goal-Action linearization; and the use of a Manner verb at the boundary crossing versus simple Path verbs.

\section{Results}

In our presentation of the results, we will first focus on bilingual Turkish production (section 4.1) and within this section we deal with selection of concepts and the verbalization of these concepts (section "The selection of

6 In sentences such as The kids are riding their bikes or I swam for two hours this morning, Path is not obligatory. We are grateful to Scott Jarvis for pointing this out to us.

7 An overview of a number of unconventional features in the Turkish stories of bilinguals can be found in Treffers-Daller and Özsoy (1995). concepts and the verbalization of these concepts"), the use of Path satellites and patterns in which those concepts are verbalized (section "The use of Path satellites"), the linearization of units of information (section "The linearization of clauses") and boundary crossings (section "Events involving a boundary crossing: incomplete acquisition?"). In section 4.2, we focus on bilingual German production, and in the final section (4.3) we summarize the results.

\subsection{Bilingual Turkish production}

The selection of concepts and the verbalization of these concepts

In preparing to speak about the movement of the father going down the manhole (Event 1/Ball story), speakers need to select which of the components of Path (Vector, Conformation or Deictic) they wish to verbalize. Turkish speakers have three basic options (see Table 2). The easiest option is to choose the deictic Motion verb git-, which expresses neither the Vector nor the Conformation, but only movement in a direction other than towards the speaker (Talmy, 2000b, p. 65). The second possibility is to use in- "descend", which conflates the movement with the Vector but does not express the Conformation, and finally gir- "enter", which conflates movement with the Vector and the Conformation. All three options are grammatical but, as we will see below, they are not used equally often by different groups. A manner verb that conflates the notion CLIMBING with the vector DOWNWARDS does not exist in Turkish, as ttrman- means CLIMB UPWARDS (Slobin, 2004).

In German, there is a greater variety of options, in that Path particles that express the Vector, runter/hinunter "downwards", etc. or the Conformation rein/hinein "into" can be combined with deictic verbs as well as manner 
Table 3. Comparison between the number of verbs with Conformation component (ENTER) in Turkish by the two bilingual groups and two monolingual groups for the Event 1/Ball story.

\begin{tabular}{llll}
\hline \hline Group comparison & Test results (two-tailed) & Outcome & $\begin{array}{l}\text { Effect size } \\
\text { Cramér's } V\end{array}$ \\
\hline B-stud and B-return & $\chi^{2}=5.341, d f 1, p<.05$ & $*$ & .254 \\
B-stud and monolingual Turks & $\chi^{2}=10.463, d f 1, p<.001$ & ${ }^{* *}$ & .310 \\
B-stud and monolingual Germans & $\chi^{2}=2.820, d f 1, p=.093$ & n.s. & n/a \\
B-return and Turkish monolinguals & $\chi^{2}=.309, d f 1, p=.578$ & n.s. & n/a \\
\hline \hline
\end{tabular}

NOTE: Here and in the following tables * significant at $p<.05,{ }^{* *}$ significant at $p>.01$.

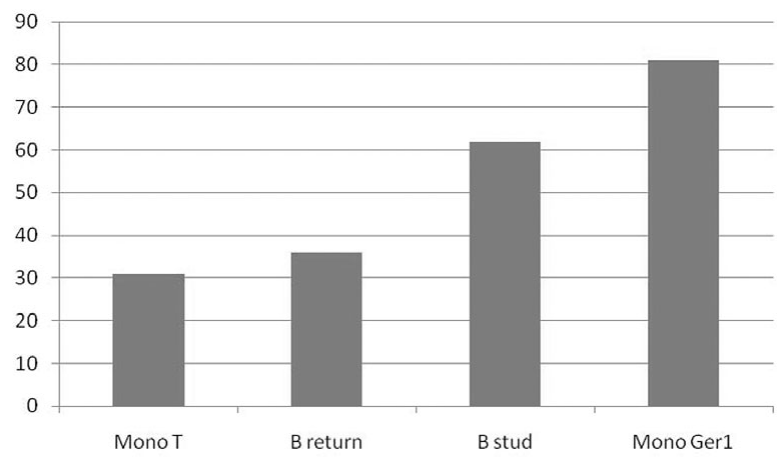

Figure 1. Percentage of structures with Conformation component (ENTER) in Turkish (first three columns), compared with German (last column) in the Event 1/Ball story.

verbs. Thus, although all three components of Path can be verbalized in both languages, there is a greater variety of expression in German due to the large number of Path particles.

Figure 1 shows that the German monolinguals differ from the Turkish monolinguals in that the former prefer to select the Conformation component of the motion event for verbalization (by choosing the Path particle rein/hinein "into") whereas the latter do not. Instead, the Turkish monolinguals prefer to select the Vector component of Path as the key concept to be verbalized, by construing this event as a movement downwards by using in- "descend". 8 Figure 1 shows how these two conceptualizations are distributed between the four groups. It may be helpful to note that the first three columns represent the percentage of occurrence of gir- "enter" as compared with other verbs used for Event 1/Ball story in Turkish by monolingual

8 There is, of course, also the option not to use a Path description in this situation by saying The father wants to get the ball. It should be mentioned here that this cannot be seen as avoidance of Path but simply as a focus on the intention of the actor. Since the focus of the present study is on the realization of Path descriptions, we do not analyze these cases. speakers of Turkish, bilingual returnees and bilingual students in German respectively; the fourth column represents rein "into" versus other Path particles in German as used by monolingual speakers of German.

In Figure 1 and all further figures we present percentages to make visual comparisons easier. The monolingual Turks produce Path descriptions that contain a Conformation component in $31 \%$ of the event construals, whereas this figure is $81 \%$ for the monolingual Germans. Importantly, the bilinguals as a group fall between the two monolingual extremes. The bilinguals in Germany (B stud) are closest to the monolingual Germans and include a Conformation component in $62 \%$ of the cases, whereas the returnees are closest to the monolingual Turkish ways of expressing this event, with only $36 \%$ of the descriptions containing a Conformation component. For the statistical analysis we used the raw data in all cases. Overall, the differences between the four groups are significant $\left(\chi^{2}=24.243, d f 3, p<.001\right.$, two-tailed $){ }^{9}$ In order to investigate this further, a series of group comparisons were carried out (see Table 3).

The significance levels and the effect sizes listed in Table 3 reveal that the bilingual students in Germany differ from monolingual Turks, in that the former choose gir"enter" most often and the latter choose in- "descend" or git- "go" most often to describe the movement of the father. The choices made by bilingual students thus resemble those of monolingual German students who choose rein- or hinein "into" most often.

As mentioned in section 3.1, some of the bilingual university students in Germany have a different migration history, as they came to Germany after the age of three and are therefore best seen as late bilinguals. If this group is further broken down into those students who arrived

9 We use several $\chi^{2}$-tests in this article and are aware that this increases the risk of a Type 1 error. However, some of the outcomes are highly significant and a Type 1 error is unlikely in these cases. In addition, all the comparisons made in this article show similar differences between the groups involved and all point in the same direction, and a Type 1 error in one of these comparisons would not alter the overall picture. 
Table 4. Choice of verbs with and without Conformation component (ENTER) in the Event 1/Ball story among two subgroups of bilingual university students in Germany.

\begin{tabular}{lrl}
\hline \hline $\begin{array}{l}\text { B Study 1 (bilingual university } \\
\text { students in Germany) }\end{array}$ & Gir- "enter" & In- "descend" \\
\hline Arrived before age $3(n=13)$ & 10 & 3 \\
Arrived after age $3(n=8)$ & 3 & 5 \\
\hline \hline
\end{tabular}

Table 5. Patterns with (redundant) Path satellites in Turkish and German.

\begin{tabular}{lll}
\hline \hline & & (Redundant) adposition \\
\hline & $\begin{array}{l}\text { Single } \\
\text { Path verb }\end{array}$ & $\begin{array}{l}\text { or satellite and Path } \\
\text { verb/Manner verb }\end{array}$ \\
\hline $\begin{array}{l}\text { Turkish } \\
\text { examples }\end{array}$ & in- "descend" & aşağ in- "downwards descends" \\
German & n.a. & içine gir- "into enter" \\
examples & & rein-steigen "into climb" \\
\hline \hline
\end{tabular}

before the age of three and those who arrived after the age of three, ${ }^{10}$ the same contrast is again observed, in that those who had had significant exposure to Turkish as spoken in Turkey (prior to coming to Germany) prefer in- "descend", whereas those who had been exposed to German since birth (and had had little contact with Standard Turkish) prefer gir- "enter" (see Table 4).

\section{The use of Path satellites}

The focus in this section is on the patterns that involve a combination of Path verbs with redundant Path satellites. Table 5 shows that in Turkish the movement of the father in Event 1 can be realized with a single Path verb in"descend", as in (5), repeated below for convenience as (16), but sometimes a redundant adposition aşağ "downwards" is added to this Path verb, as in (17). This particle is redundant because it represents a verbalization of the Vector component of Path, and the verb represents the Vector too. The use of the adposition is similar to the use of particles in a German separable verb construction, such as runter-klettern "to climb down", but in German this particle is not redundant (see section "Path"). Path and Goal can also be expressed together, as in (18),

10 Five students in the second subgroup came to Germany after the age of fourteen or later. The other three came to Germany at an earlier stage but went back to Turkey for one or more years during primary or secondary school. We grouped these together because these eight had had more contact with Turkish as spoken in Turkey than the students in the first subgroup. where iç(ine) "into" represents the Path and kanalizasyon "manhole" the Goal. Table 5 gives examples of redundant adpositions in Turkish and constructions in German where the adposition/satellite is not redundant.

(16) Daha sonra baba-s1 in-ip al-1yor Then later father-Poss descend-Ger get-Prog "After that, having descended, his father gets (it)."

(speaker 9, Mono T, age 20)

(17) adam aşağı-ya iniyor Man downwards-Dat descend-Prog The man descends downwards."

(speaker 1, B return, age 20)

(18) Baba kanalizasyon-un iç-in-e gir-iyor father manhole-Gen in-Poss-Dat go-Prog "The father goes into the manhole."

(speaker 9, B Stud, Bielefeld, age 24)

In German, a satellite is normally used to express Path, as in (19). Path and Goal can be expressed in the same sentence, as in (20), where in "in" is the Path and den Gully the Goal of the movement. In (21), both in "in" and rein "into" are used, but neither of these satellites is redundant, because each expresses a different component of Path: the first one (in) refers to the Vector, and the second one (rein "into $=$ to the inside of") to the Conformation component of Path. Lastly, it is also possible to describe the event without using a Motion verb, Path or Goal, as in (22).

(19) Der Vater geht auch rein.

The father goes also in

"The father goes in too."

(speaker 13, Mono Ger 1 Bielefeld, age 13)

(20) Dann will der Vater daraufhin in den Gully steigen. Then wants the father therefore in the-Acc gully climb

"And therefore the father wants climb into the gully."

(speaker 18, Mono Ger 1, Bielefeld, age 14)

(21) Der Vater sucht also geht in den

The father searches therefore goes in the-Acc

Gullydeckel rein

manhole cover into

"The father searches and then goes into the manhole"

(speaker 19, Mono Ger 1, Bielefeld, age 13)

(22) Der Vater will dann den Ball holen

The father wants then the ball get

"The father wants to get the ball then."

(speaker 1, Mono Ger 1, Bielefeld, age 14)

Given the typological differences between Turkish and German, we expected monolingual speakers of German and Turkish to use Path satellites in different ways in narrating the Event 1/Ball story. In V-framed languages such as Turkish, Path is not normally expressed in a 
Table 6. Comparison between structures containing a Path satellite in Turkish compared with German in the Event 1/Ball story.

\begin{tabular}{llll}
\hline \hline Group comparison & Test results (two-tailed) & Outcome & $\begin{array}{l}\text { Effect size } \\
\text { (Cramér's } V \text { ) }\end{array}$ \\
\hline Mono T and Mono Ger & $\left(\chi^{2}=18.876, d f=1, p<.01\right)$ & $* *$ & .439 \\
B-stud and B-return & $\left(\chi^{2}=1.477, d f=1, p=.224\right)$ & n.s. & $\mathrm{n} / \mathrm{a}$ \\
B-stud and monolingual Turks & $\left(\chi^{2}=16.539, d f=1, p=<.01\right)$ & $* *$ & .376 \\
B-stud and monolingual Germans & $\left(\chi^{2}=.783, d f=1, p=.379\right)$ & n.s. & $\mathrm{n} / \mathrm{a}$ \\
B-return and German monolinguals & $\left(\chi^{2}=3.539, d f=1, p=.060\right)$ & Trend & .233 \\
B-return and Turkish monolinguals & $\left(\chi^{2}=6.077, d f=1, p=.014\right)$ & $*$ & .243 \\
\hline \hline
\end{tabular}

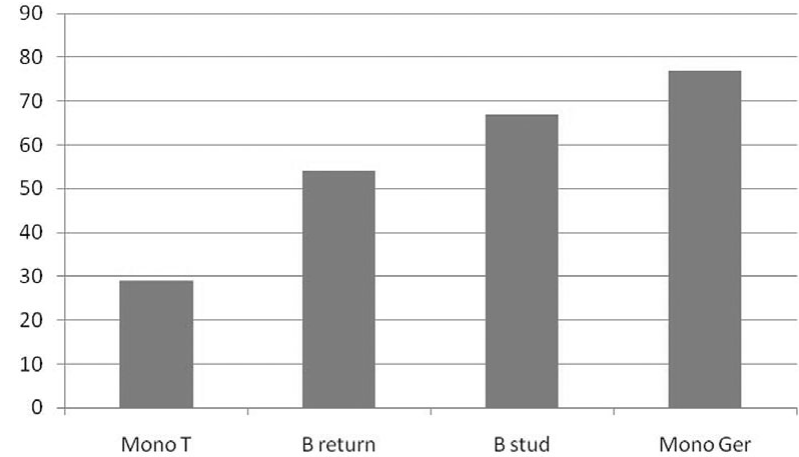

Figure 2. Percentage of structures containing a Path satellite in Turkish (first three columns), compared with German (last column) in the Event 1/Ball story.

Path particle, but in the Verb. A second expression of Path in the form of a satellite is redundant, even though it is not ungrammatical. We expected monolingual German speakers to use more Path satellites than Turkish monolinguals, given the availability of a wide variety of Path satellites and the fact that more than one can be used per clause in German (Bamberg, 1994).

Figure 2 shows the percentages of narrations that contain a Path satellite. The first three columns in this figure represent the percentage of Path satellites that accompany Path verbs used to describe this event in Turkish, and the last column shows the percentage of German Path particles used in constructions chosen by monolingual Germans.

The four groups differ from each other in predictable ways, with the monolingual Turkish speakers using the lowest number of Path satellites (29\%), and the monolingual Germans the highest number of Path satellites (77\%), whilst the bilingual groups occupy the middle ground. The returnees produce these in $54 \%$ of the cases and are thus closer to the monolingual Turks, whereas the bilingual students in Germany are closer to the monolingual German preferences, constructing verbs with Path satellites in $67 \%$ of the cases.
Overall the differences between the four groups are significant $\left(\chi^{2}=25.916, d f=3, p<.01\right)$. Table 6 shows the differences between the groups in detail.

It is not surprising that the differences between the two extremes - the monolingual Turkish group and the monolingual German group - are significant because these are the result of the typological differences between the two languages. However, the differences between the monolingual Turkish group and the two bilingual groups cannot be explained by language type, as all three groups told the story in Turkish. The bilinguals occupy a middle position between the two monolingual groups. Although the difference between the two bilingual groups is not significant, the effect sizes shed an interesting new light on the variation between these two bilingual groups. The largest effect size is found in a comparison between the two monolingual groups (Cramér's $V=$ .439), and the second-largest effect size is obtained in a comparison between the bilinguals in Germany and the monolingual Turks (Cramér's $V=.376$ ). Thus the bilinguals in Germany are clearly further removed from the monolingual Turks than the returnees (Cramér's $V=.243)$. When compared with the monolingual Germans, the bilinguals in Germany are not significantly different in their use of Path satellites, whereas the difference between the returnees and the monolingual Germans approaches significance.

\section{The linearization of clauses}

With respect to the linearization of clauses, we predicted that the bilinguals in Germany would express the Goal of the father's action (to fetch the ball) in the Event 1/Ball story after the action itself (Action-Goal sequence) when speaking Turkish, although the default pattern for such a structure in standard Turkish is the reverse (Goal- Action sequence). The results are shown in Figure 3.

Figure 3 shows that the monolingual Germans produce only Action-Goal sequences, whereas the monolingual Turks produce mainly Goal-Action sequences $(92 \%$ of the cases). The bilinguals are again in a middle position, 
Table 7. Comparison of linearization of Action-Goal versus Goal-Action sequences in the Event 1/Ball story.

\begin{tabular}{llll}
\hline \hline Group comparison & Test results (two-tailed) & Outcome & $\begin{array}{l}\text { Effect size } \\
\text { Cramér's } V\end{array}$ \\
\hline Mono T and Mono Ger & (Fisher exact, $p<.01)$ & $* *$ & .831 \\
B-stud and B-return & (Fisher exact, $p=.210)$ & n.s. & $\mathrm{n} / \mathrm{a}$ \\
B-stud and monolingual Turks & (Fisher exact, $p<.01)$ & $* *$ & .515 \\
B-stud and monolingual Germans & (Fisher exact, $p=.063)$ & Trend & .399 \\
B-return and Turkish monolinguals & (Fisher exact, $p=.052)$ & Trend & .321 \\
\hline \hline
\end{tabular}

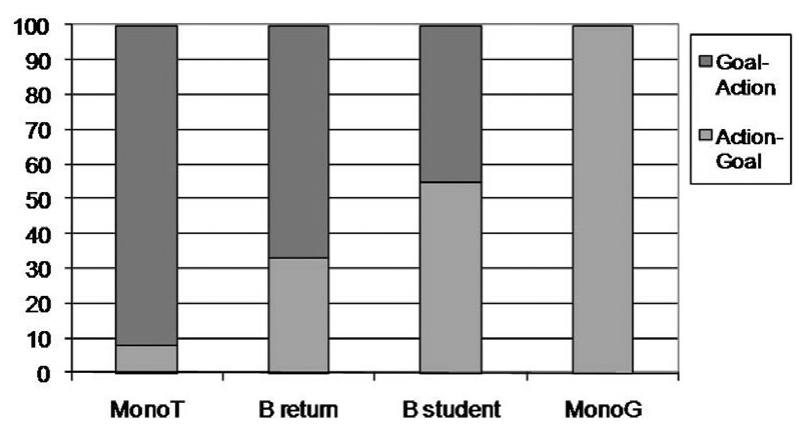

Figure 3. Percentage of linearization of Action-Goal versus Goal-Action sequences in the Event 1/Ball story (in percentages) in Turkish (first three columns) and German (last column).

but the results for the returnees approach the frequencies found among monolingual Turks: 33\% Action-Goal and $67 \%$ Goal-Action sequences. Among the bilingual students in Germany, Action-Goal sequences are more common (55\%) than Goal-Action sequences $(45 \%)$, which shows they are closer to the German monolingual patterns. Overall, the differences in the linearization of this event are highly significant $\left(\chi^{2}=22.229, d f=3, p<\right.$ .001 , two-tailed). Table 7 shows the differences between the groups in detail.

The difference in the linearization of the event between the monolingual Turks and the monolingual Germans is highly significant and shows a large effect size. This reflects the preferred patterns of the two languages as we compare narrations in Turkish and German in this case. The difference between the two bilingual groups is not significant. However, both bilingual groups differ from the monolingual groups and we conclude that both bilingual groups occupy again a middle position between the monolingual preferences, but only the bilingual group in Germany shows highly significant differences from the monolingual Turkish group. The difference between the bilingual group in Germany and the monolingual Turks is therefore more pronounced than the difference between the returnees and the monolingual Turks, which is also confirmed by the effect sizes.
Table 8. Use of Path and Manner verbs in Turkish and German (Event 1/Ball story).

\begin{tabular}{lll}
\hline \hline Group & $\begin{array}{l}\text { Path/deictic } \\
\text { verbs }\end{array}$ & $\begin{array}{l}\text { Manner } \\
\text { verbs }\end{array}$ \\
\hline $\begin{array}{l}\text { Turkish stories by Turkish monolinguals } \\
(n=68)\end{array}$ & 61 & 0 \\
$\begin{array}{l}\text { Turkish stories both groups of bilinguals } \\
(n=84)\end{array}$ & 82 & 0 \\
$\begin{array}{l}\text { German stories by German } \\
\text { monolinguals }(n=30)\end{array}$ & 7 & 18 \\
\hline \hline
\end{tabular}

\section{Events involving a boundary crossing: incomplete acquisition?}

As we have seen in section 1.2, even advanced L2 learners often find it difficult to acquire the boundary crossing constraint. We might therefore expect that the bilinguals did either not fully acquire the boundary crossing constraint in Turkish or are influenced by the absence of this constraint in German. They might therefore use tirman- "climb upwards" for the downward movement of the Figure in the Event 1/Ball story, which would violate the boundary crossing constraint in Turkish. As Table 8 demonstrates, this was not the case. Neither the monolingual nor the bilingual Turkish speakers use Manner verbs at this boundary crossing in the Turkish stories, whereas the German monolinguals ${ }^{11}$ clearly use more Manner verbs here than deictic verbs.

The differences between the three groups are statistically significant $\left(\chi^{2}=115.325, d f 2, p<.001\right)$. This is a clear indication that the boundary crossing constraint applies in the event and that all bilinguals are fully aware of this constraint. Thus, incomplete acquisition of the boundary constraint is not an issue in this context.

11 The first subgroup of German monolinguals (M Ger1) is used for the comparison with all Turkish descriptions in this section. The second subgroup (M Ger2) is used as an additional control group for the picture descriptions in German of the bilinguals (section 4.2). 
Table 9. Comparison of the use of rennen and other Motion verbs in the Event 2/Bank story.

\begin{tabular}{llll}
\hline \hline Group comparison & Test results (two-tailed) & Outcome & Effect size (Cramer's $V$ ) \\
\hline B-stud and B-return & $\left(\chi^{2}=.817, d f=1, p=.366\right)$ & n.s. & n/a \\
B-stud and monolingual Germans & $\left(\chi^{2}=2.504, d f=1, p=.114\right)$ & n.s. & n/a \\
B-return and German monolinguals & $\left(\chi^{2}=5.251, d f=1, p=.022\right)$ & $*$ & .331 \\
\hline \hline
\end{tabular}

\subsection{Bilingual German productions}

In this section the focus is on the German productions of bilinguals and monolinguals. As explained in section 3.2, the bilinguals told a different story in German and in Turkish, to avoid translation effects. From this second story we chose an event in which a robber enters a bank, which clearly involves a boundary crossing. ${ }^{12}$ The following analysis focuses on this motion event (from now on, the Event 2/Bank story). Again there are several ways to describe this event, but if participants choose to express the boundary crossing, the following three verbs are used most often: rennen "run", laufen "run/walk" and gehen "go", or hinein-gehen "go into". The monolinguals use only these verbs and so do most of the bilinguals. ${ }^{13}$ The verb rennen is a clear Manner verb and the verb hineingehen is a general Motion verb with a separable particle that expresses Path. Laufen is more difficult to classify (and to translate into English). Originally this verb meant "move very quickly, run". It seems, however, to have lost some of its Manner qualities. For many speakers of present-day German, the notion of speed is not necessarily attached to the verb laufen (Drosdowski, 1989, p. 406). We therefore conclude that the only clear Manner verb that is used in the stories which contain this motion event is the verb rennen "run", and we compare its use with the use of all other verbs by the participants from all four groups who related this event in German. Figure 4 shows the distribution of these verbs.

The monolingual Germans use rennen for the description of this boundary crossing in $54 \%$ of the event construals and other verbs in $46 \%$ of the cases. By contrast, returnees prefer other Motion verbs, such as laufen or gehen, and use rennen in only $28 \%$ of the cases. The bilinguals in Germany find themselves between the two other groups. They prefer rennen in 39\% of the event descriptions and other Motion verbs in $61 \%$ of the cases.

The overall difference between the three groups approaches significance for a two-tailed test $\left(\chi^{2}=3.515\right.$,

12 The picture stories are available from the first author of this article.

13 The only exceptions are three alternative realizations with stürmt in die Bank "storms into the bank", dringt in die Bank ein "intrudes into the bank" and one with kommt in die Bank "comes into the bank". A quantitative analysis seems not to be useful with only these few cases.

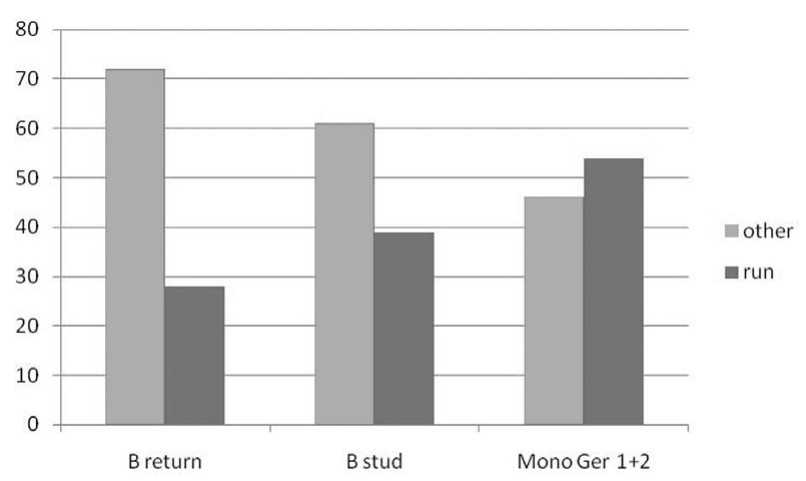

Figure 4. Percentage of use of rennen "run" in relation to other Motion verbs among monolinguals and bilinguals used to describe the Event 2/Bank story in German by all groups.

$d f=2, p=.061)$ and are thus significant with a one-tailed test. A detailed picture of the group differences is given in Table 9.

Neither the differences between the two bilingual groups, nor the differences between the bilinguals in Germany and the monolingual Germans are significant. Only the differences between the returnees and the monolingual Germans are significant, with a moderate effect size. This is an indication that the returnees are farther away from the preferences of the monolingual Germans than the bilinguals in Germany, with respect to their use of Manner verbs in boundary crossings.

Interestingly, three of the returnees produce constructions in which Manner is subordinate to Path, which is characteristic for V-languages such as Turkish, but unconventional in German. Thus, in (23), the speaker uses a participle rennend "running", to express the Manner of movement of the man, while the main verb is a Path verb, eintreten "enter". In (24) the main verb is the deictic verb kommen, which is accompanied by a gerund that expresses the Manner of movement, laufend "walking".

(23) Der Mann der äh rennend in die Bank The man who ehm running in the bank eingetreten ist entered is $(\ldots)$ "The man who entered the bank running (...)." (speaker 34, returnee, age 21) 
(24) Ein Räuber, so sieht es aus, kommt laufend A burglar, so looks it out comes walking ins (sic) Bank

into bank

"A burglar, that's what it looks like, comes walking into the bank."

(speaker 17, returnee, age 19)

The monolingual Germans and the bilinguals in Germany do not use the Path verb eintreten at all in this context, nor do they use constructions in which Manner is subordinate to Path. A statistical analysis of the group differences is not possible since there are only a few examples of these constructions in the data from the returnees.

\subsection{Summary}

In this study we have compared event construals from bilinguals in Germany and bilingual returnees in Turkey with those from monolinguals of both languages. Our analysis confirms the well-known contrasts between the language-specific patterns for the construal of motion events in Turkish and German: all Turkish bilingual participants select Path verbs or deictic verbs to verbalize a typical boundary crossing in a Turkish narrative and avoid using a Manner verb in this context, whereas monolingual Germans most often use Manner verbs in German to verbalize the same motion event. The two bilingual groups in the present study are thus sensitive to the typological characteristics of both languages, but at the same time there are subtle differences in how they construe motion events, either between these two groups of bilinguals or between the bilinguals on the one hand and monolinguals of each language on the other hand. These differences are found in (a) the selection of concepts for verbalization in Turkish and German, (b) the use of Path satellites in Turkish, (c) the linearization of clauses in Turkish and (d) the choice of Manner verbs in boundary crossings in German.

When speaking Turkish, the bilingual students in Germany often choose concepts or patterns that resemble those used by monolingual Germans, whereas the returnees in Turkey opt for those that are most commonly found among monolingual Turks. When speaking German, the latter choose Manner verbs less often in a boundary crossing situation than the bilinguals in Germany or monolingual Germans.

Finally, we have seen that the choices of all bilingual informants are generally grammatical, but sometimes slightly unconventional, and reflect statistical departures from the preferred patterns of the monolinguals rather than the use of ungrammatical patterns.

\section{Discussion and conclusion}

In this section we will evaluate different explanations of the findings. In particular we will focus on whether or not the patterns of event construal found in our data reflect cross-linguistic effects, and if so, at what levels these effects take place.

First of all, we would like to reiterate that the choices made by the bilinguals in both groups are grammatical and semantically appropriate in Turkish. Second, we explored the possibility that bilinguals in Germany or the returnees had not fully acquired the typical Turkish ways to construe a motion event. This could manifest itself, for example, in incomplete acquisition of the boundary crossing constraint, which is difficult for some L2 learners (Cadierno \& Ruiz, 2006; Treffers-Daller \& Tidball, in prep.). We do not believe this is the case, because the bilinguals do not select Manner verbs in these constructions. As most of the bilinguals in Germany had had no formal instruction in Turkish, we assume that this constraint is acquired by learners of V-languages irrespective of schooling. This is not implausible, as AksuKoç (1994), Özçalışkan and Slobin (2000) and Allen et al. (2007) demonstrate that as early as three years of age, children are tuned to the language-specific lexicalization patterns of their language.

Third, we explored the possibility that the choices of the bilinguals in Germany could be explained as a form of simplification. We do not think that this is the case, first of all because gir- "enter" is not easier than in- "descend" or git- "go", either semantically or morphosyntactically, and all three verbs are listed in basic vocabularies, such as Tezcan's (1988) Turkish-German basic vocabulary. In fact, one could argue that gir- "enter" is conceptually more complicated than the two other options, because this verb expresses the Vector as well as the Conformation. If simplification were the main factor behind the students' choices, one would expect the deictic verb git- "go" to be the preferred verb, as it expresses neither the Vector nor the Conformation. The data clearly show that the bilinguals do not prefer git- "go", which makes it unlikely that their choices are motivated by simplification. The other variables studied here are not likely candidates for simplification either: adding a (redundant) Path particle to a Motion expression does not simplify its structure, and there is no reason to assume that GOAL-ACTION sequences are more difficult than ACTION-GOAL sequences. One might, of course, argue that when the returnees choose laufen or gehen instead of the Manner verb rennen, this represents a simplification, but we need to bear in mind that some students choose to express manner in a subordinate clause following the main clause, which clearly is not a case of simplification.

We believe that an interaction between language dominance and cross-linguistic influence is the reason for the patterns found among the two groups of bilinguals. For this claim we have gathered three types of evidence, as explained in section 2. First of all we studied the 
intragroup homogeneity for each group of bilinguals, and each variable. As the different variants occur in all groups, but in different proportions, there is a considerable amount of within-group variation for some variables. The evidence for intragroup homogeneity is therefore not very strong, even though one of the two variants is clearly the favourite in each group. For the selection of concepts, for example, the bilingual students in Germany select gir- ("enter") in more than $62 \%$ of the cases and the returnees in $36 \%$ of the cases. Interestingly, we found that the variability within the group of bilinguals in Germany was related to their exposure to Turkish in early childhood, with those who had had more contact with Turkish as spoken in Turkey choosing gir- less frequently.

The differences between the proportions of usage of the different variants are large enough to become significant in intergroup comparisons between the two groups of bilinguals, or in comparisons between the bilinguals on the one hand and the monolinguals of each language on the other hand. The evidence for intergroup heterogeneity is therefore strong. The results also point to the existence of strong cross-linguistic performance congruity. For bilinguals in Germany there is ample evidence of congruity between the patterns found in the source language (German) among monolingual speakers of German and in the recipient language (Turkish): both groups prefer to select the same component of Path (the Conformation) for the Event 1/Ball story, they both frequently use a satellite to express Path (even though this is redundant in Turkish) and they both favour ACTIONGOAL sequences over GOAL-ACTION sequences. For returnees in Turkey, we have found evidence for crosslinguistic performance congruity between the patterns found in the source language (Turkish) and the recipient language (German), in that returnees use very few Manner verbs in boundary crossings in German, and some students use the reverse pattern of event conflation in German (with Manner subordinate to Path).

The results provide sufficient quantitative and qualitative evidence to warrant the conclusion that crosslinguistic effects have taken place. The crucial question that needs to be answered now is at what level these effects operate, i.e., whether cross-linguistic influence has led to a change in the conceptual categories in the speakers' long-term memory, whether it has resulted in the widening or narrowing of the meaning of lexical entries in the lexicon, or whether transfer has taken place during processing of information in either the Conceptualizer or the Formulator. Of course, it is difficult to answer these questions fully in a study in which we do not have access to processing data, but only to the products of processing, namely the stories produced by different speaker groups. We do believe, however, that our data allow us to argue that some answers are more likely to be correct than others.
The data do not indicate that the conceptual categories stored in the speakers' long-term memory have changed under the influence of the dominant language, because bilinguals and monolinguals both make conceptual distinctions between movements in different directions, such as a movement INTO versus a movement DOWNWARDS. The Event 1/Ball story can be interpreted in either way, but the bilinguals in Germany prefer the 'German interpretation' of the event, and the returnees prefer the 'Turkish interpretation'. In addition, all bilinguals can map these two concepts onto verbs such as gir- "enter" or -in "descend" in target-like ways. They do not use tırman "climb in an upwards manner" for movements downwards either. Therefore there is no evidence that the conceptual categories distinguished by the bilinguals have changed. In other words, there is no evidence for concept transfer, as defined by Jarvis (2007), and we cannot conclude from our data that languagespecific categories or patterns influence cognition in general as suggested by Lucy $(1992 \mathrm{a}, \mathrm{b})$ or Danziger (2001).

We do not believe that the semantic information that is part of the lemmas in the lexicon is affected in these cases either: the meaning of the verb gir"enter" has not been extended under the influence of German, because examples from monolingual Germans show that it is acceptable to use this verb in the context of the Event 1/Ball story. It is therefore unlikely that the lemma of this verb has changed under the influence of German.

Finally, there is no evidence for widespread syntactic transfer from Turkish (or even a complete change in word order in Turkish). The linearization is found in specific ACTION-GOAL sequences, not across a wide variety of structures that consist of a main and a subordinate clause. Therefore, we do not think that transfer takes place at the level of the Formulator, when the syntactic building procedures are accessed. Again it is important to note that the ACTION-GOAL sequences are not ungrammatical or new: they are just unconventional (Doğruöz \& Backus, 2009).

As it is in THE CONSTRUAL OF THE EVENT that the bilinguals differ from the monolinguals, we believe the most likely explanation for the phenomena is that transfer operates during thinking-for-speaking, that is, during the online processing of conceptual knowledge in the planning phase of speech production, which results in the production of the preverbal message. It is clear that the participants, when they interpret the pictures, must make a link between the visual information they have been given (that is extralinguistic information) and the mental representations stored in memory. In other words, they need to select particular concepts and structures that best represent the visual information. We hypothesize that it is in this selection process that cross-linguistic 
influence, particularly from the dominant language, takes place.

As we have argued in section 3.1, for bilinguals in Germany the dominant language is German. In preparing to verbalize the Event 1/Ball story, they select the concept ENTER, which is also the preferred conceptualization of the German monolinguals. This concept is then mapped onto the corresponding lemma from the non-dominant language. Thus the dominant language influences THE CHOICE OF THE CONCEPT for the event in question. As this process starts with language (German), and ends, via cognition, with language (Turkish) we consider this to be an example of conceptual transfer (Jarvis \& Pavlenko, 2008, p. 115).

Additional evidence for transfer from German in the conceptualization of Path can be found in the fact that bilinguals in Germany combine Path verbs with redundant Path particles (which express the Vector) when speaking Turkish. It is likely that the highly frequent constructions with separable particles in German are routinized, which may result in bilinguals in Germany transferring these constructions to Turkish in patterns such as aşağl in"downwards descends".

Similar explanations can be advanced to explain the source of the ACTION-GOAL sequences in Turkish as spoken by bilinguals in Germany. Multi-clause syntactic frames such as the ACTION-GOAL sequences that are memorized independently of lexical content (Pawley \& Syder, 2000) become entrenched through frequent usage in the dominant language (German), and are then also selected in the planning of event construals in the nondominant language (Turkish).

Conceptual transfer in the opposite direction takes place among the returnees who are dominant in Turkish and are used to expressing Manner subordinate to Path, and then start applying these patterns to the non-dominant language, German, which results in constructions such as kommt laufend ins Bank "comes running into the bank" in the construals of the Event 2/Bank story.

The results discussed in this article constitute clear evidence for Slobin's (1987, et seq.) Thinking-forSpeaking Hypothesis, as well as for Jarvis's (2007) Conceptual Transfer Hypothesis, which states that a person's patterns of language use in one language can reflect the concepts and patterns of conceptualization that the person has acquired as a speaker of another language. As there is no evidence for changes in the long-term memory of bilinguals (either at the conceptual level or at the lemma level), the evidence suggests that the transfer phenomena are dynamic rather than static (Grosjean, 2008). We also concur with Jarvis that it is the statistical tendencies rather than categorical patterns that reveal conceptualization transfer. In our dataset, the different options for construing the events were used by all groups, but in very different proportions. The phenomena under investigation are therefore best seen as examples of covert inter-systemic transfer (Mougeon et al., 2005).

The incorporation of the notion of language dominance into this framework helps to explain the direction of transfer for the two groups of bilinguals who have grown up with two first languages and for whom models which rely on the distinction between L1 and L2 are less suitable. As we have shown above, the direction of conceptualization transfer can be predicted on the basis of language dominance. It is the conceptualization patterns that speakers routinely rely upon when using the dominant language that become so entrenched that they are also activated when the speaker plans utterances in the nondominant language. This then results in the transfer of the conceptualization patterns found. In our study, language dominance at the level of society is reflected at the level of the individual, in that those students who live in Germany are German-dominant and those who live in Turkey are Turkish-dominant (see Daller et al., 2003; Treffers-Daller et al., 2007).

The current study also illustrates Grosjean's (1998) point that a bilingual's language use may change over time: as the environment changes, the needs for particular language skills also change, and thus the language dominance profiles may be reversed. This explains the differences in individual language dominance between the bilinguals who have remained in Germany and the returnees who returned to Turkey. Whether or not individual or societal dominance and individual language dominance is the crucial factor behind conceptualization transfer remains difficult to determine, because the individual uses the conceptualization patterns that are dominant in a particular speech community. A possible way forward in this discussion is to study to what extent measurements of lexical richness in individuals on the one hand, and measures of "embeddedness" in the dominant culture of a particular society on the other hand, can be used as predictors of the use of contact-induced phenomena by these same speakers. It may be more difficult to measure the degree to which an individual bilingual is embedded in the dominant culture, but if detailed information about the networks in which a speaker participates could be gathered, we may be able to disentangle the effects of individual versus societal language dominance on transfer. Analyses of bilinguals who have recently moved to a new speech community and who will not have access to the conceptualization patterns that are habitually used in that new community could also shed some light on this issue. It is likely that recent arrivals in a country will not experience the same transfer effects from the culturally dominant language as a bilingual who has had regular access to the dominant language of the environment over a prolonged period of time. The analysis of conceptualization patterns found among recent returnees who were recorded within a year after returning to Turkey may shed new light upon 
the time it takes to adapt to the conceptualization patterns used in the new country.

Another issue that deserves to be investigated further is to what extent language dominance itself is static or dynamic. If we accept that bilinguals may find themselves on various points along a situational continuum which induces either a monolingual or a bilingual speech mode (Grosjean, 2008, p. 17), then the activation of a particular language may lead to that language being TEMPORARILY dominant, and in a different situation the other language may be activated and become dominant for a short period of time. If the dominant language can indeed change rapidly, this may explain why we find bidirectional transfer among bilinguals: transfer takes place from the dominant language to the non-dominant language, but depending on the situation in which the speakers find themselves, a different language may be dominant. A crucial issue here is, of course, whether the construct of language dominance is taken to refer to a speaker's competence or to their performance in their two languages or whether it taps into the ways in which bilinguals process linguistic and extralinguistic information. We hope to return to these issues in another article.

\section{Appendix 1: Event 1/the Ball story}
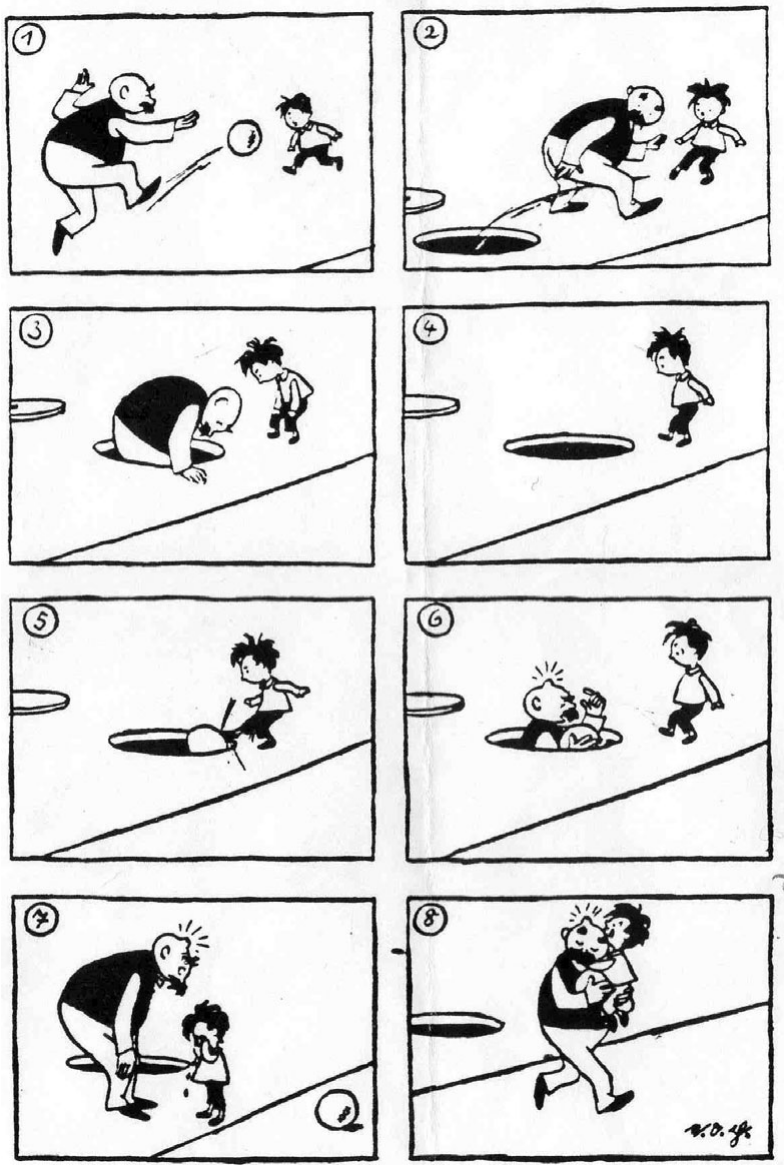

Appendix 2: Event 2/the Bank story
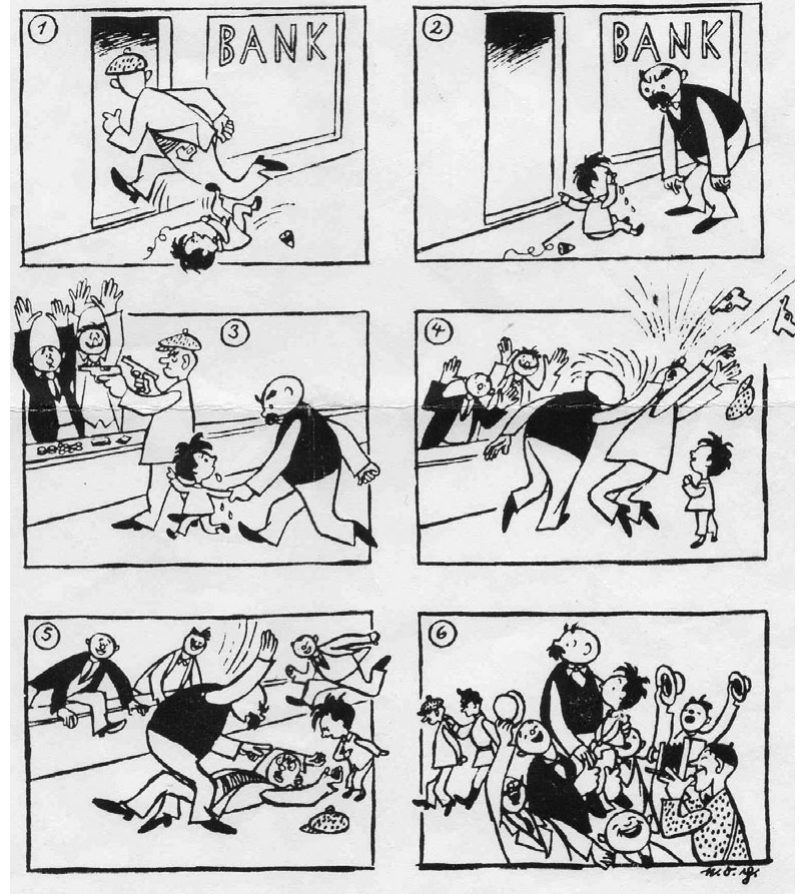

\section{Bibliography}

Aksu-Koç, A. (1994). Development of linguistic forms: Turkish. In R. Berman \& D. Slobin (eds.), Relating events in narrative: A crosslinguistic developmental study, pp. 329385. Hillsdale, NJ: Lawrence Erlbaum Associates.

Allen, S., Özyürek, A., Kita, S., Brown, A., Furman, R., Ishizuka, T., \& Fuji, M. (2007). Language-specific and universal influences in children's syntactic packaging of Manner and Path: A comparison of English, Japanese and Turkish. Cognition, 102, 16-48.

Baker, C., \& Jones, S. P. (1998). Encyclopedia of bilingualism and bilingual education. Clevedon: Multilingual Matters.

Bamberg, M. (1994) Development of linguistic forms: German. In R. Berman \& D. Slobin (eds.), Relating events in narrative: A crosslinguistic developmental study, pp. 189238. Hillsdale, NJ: Lawrence Erlbaum Associates.

Berman, R. A., \& Slobin, D. I. (1994). Relating events in narrative: A crosslinguistic developmental study. Hillsdale, NJ: Lawrence Erlbaum Associates.

Cadierno, T. (2008). Learning to talk about Motion in a foreign language. In P. Robinson \& N. C. Ellis (eds.), Handbook of cognitive linguistics and second language acquisition, pp. 239-275. London: Routledge.

Cadierno, T., \& Ruiz, L. (2006) Motion events in Spanish L2 acquisition. Annual Review of Cognitive Linguistics, 4, 183-216.

Carroll, M., \& von Stutterheim, C. (2003). Typology and information organization: Perspective taking and languagespecific effects in the construction of events. In A. Ramat (ed.), Typology and second language acquisition, pp. 365402. Berlin: de Gruyter. 
Choi, S., \& Bowerman, M. (1991). Learning to express motion events in English and Korean: The influence of languagespecific lexicalization patterns. Cognition, 41, 83-121.

Daller, H. (1999). Migration und Mehrsprachigkeit. Der Sprachstand türkischer Rückkehrer aus Deutschland. Spracherwerb und Sprachverlust [Multilingualism and migration. The language proficiency of Turkish returnees from Germany]. Frankfurt: Peter Lang Verlag.

Daller, H. (2005). Migration und bilinguale Sprachentwicklung. Türkische Rückkehrer aus Deutschland [Migration and bilingual language development. Turkish returnees from Germany]. In V. Hinnenkamp \& M. Meng (eds.), Sprachgrenzen überspringen. Sprachliche Hybridität und polykulturelles Selbstverständnis [Crossing language boundaries. Linguistic hybrids and poly-cultural identities, Vol. 32 Schriften zur deutschen Sprache/Institut fuer deutsche Sprache], pp. 325-345. Tübingen: Narr.

Daller, H., \& Grotjahn, R. (1999). The language proficiency of Turkish returnees from Germany: An empirical investigation of academic and everyday language proficiency. Language, Culture and Curriculum, 12 (2), 156-172.

Daller, H., van Hout, R., \& Treffers-Daller, J. (2003). Lexical richness in spontaneous speech of bilinguals. Applied Linguistics, 24 (2), 197-222.

Daller, M. H., Yıldız, C., De Jong, N., Kan, S., \& Başbağı, R. (in press). Language dominance in Turkish-German bilinguals: Methodological aspects of measurements in structurally different languages. In M. H. Daller (ed.), The measurement of bilingual proficiency (International Journal of Bilingualism, special issue 2011).

Danziger, E. (2001) Relatively speaking: Language, thought and kinship in Mopan Maya (Oxford Studies in Anthropological Linguistics). Oxford: Oxford University Press.

Doğruöz, A. S., \& Backus, A. (2007). Postverbal elements in immigrant Turkish: Evidence of change? International Journal of Bilingualism, 11 (2), 185-221.

Doğruöz, A. S., \& Backus, A. (2009). Innovative constructions in Dutch Turkish: An assessment of ongoing contact-induced change. Bilingualism: Language and Cognition, 12 (1), 4164.

Drosdowski, G. (1989). Duden. Das Herkunfstwörterbuch der deutschen Sprache. Mannheim: Dudenverlag.

Gass, S. (1996). Second language acquisition and linguistic theory: The role of language transfer. In C. Ritchie \& T. K. Bhatia (eds.), Handbook of second language acquisition, pp. 317-340. San Diego: Academic Press.

Göksel, A., \& Kerslake, C. (2005). Turkish: A comprehensive grammar. London and New York: Routledge.

Grosjean, F. (1997). The bilingual individual. Interpreting, 2 $(1 / 2), 163-187$

Grosjean, F. (1998). Studying bilinguals: Methodological and conceptual issues. Bilingualism: Language and Cognition, $1,131-149$.

Grosjean, F. (2008). Studying bilinguals. Oxford: Oxford University Press.

Hamers, J. F., \& Blanc, M. H. (2000). Bilinguality and bilingualism. Cambridge: Cambridge University Press.

Haugen, E. (1950). The analysis of linguistic borrowing. Language, 26 (2), 210-231.
Heine, B., \& Kuteva, T. (2008). Constraints on contact-induced linguistic change. Journal of Language Contact, Thema 2, 57-90. www. jlc-journal.org.

Helms-Park, R. (2001). Evidence of lexical transfer in learner syntax: The acquisition of English causatives by speakers of Hindi-Urdu and Vietnamese. Studies in Second Language Acquisition, 23 (1), 71-102.

Helms-Park, R. (2003). Transfer in SLA and creoles: The implications of causative serial verb constructions in the interlanguage of Vietnamese ESL learners. Studies in Second Language Acquisition, 25 (2), 211-244.

Hickmann, M., \& Hendriks, H. (2006). Static and dynamic location in French and English. First Language, 26 (1), 103-135.

Hohenstein, J., Eisenberg, A., \& Naigles, L. (2006). Is he floating across or crossing afloat? Cross-influence of L1 and L2 in Spanish-English bilingual adults. Bilingualism, Language and Cognition, 9 (3), 249-261.

Inagaki, S. (2001). Motion verbs with goal PPs in the L2 acquisition of English and Japanese. Studies in Second Language Acquisition, 23 (2), 153-170.

Jarvis, S. (2000). Methodological rigor in the study of transfer: Identifying L1 influence in the interlanguage lexicon. Language Learning, 50 (20), 245-309.

Jarvis, S. (2007). Theoretical and methodological issues in the investigation of conceptual transfer. Vigo International Journal of Applied Linguistics, 4, 43-71.

Jarvis, S., \& Pavlenko, A. (2008). Crosslinguistic influence in language and cognition. New York and London: Routledge.

Johanson, L. (2002) Structural factors in Turkic language contacts. Richmond: Curzon.

Kopecka, A. (2006). The semantic structure of motion verbs in French. Typological perspectives. In M. Hickmann \& S. Robert (eds.), Space in languages: Linguistic systems and cognitive categories, pp. 83-101. Amsterdam: John Benjamins.

Kornfilt, J. (1997). Turkish. London and New York: Routledge.

Kramer, J. 1981. Die Übernahme der deutschen und der niederländischen Konstruktion Verb + Verbzusatz durch die Nachbarsprachen. In W. Meid \& K. Heller (eds.), Sprachkontakt als Ursache von Veränderungen der Sprachund Bewusstseinsstruktur: Eine Sammlung von Studien zur sprachlichen Interferenz, pp. 129-140. Innsbruck: Institut für Sprachwissenschaft der Universität Innsbruck.

Langacker, R. W. (2000) Grammar and conceptualisation. Berlin: Mouton de Gruyter.

Levelt, W. (1989). Speaking: From intention to articulation. Cambridge, MA: MIT Press.

Levinson, S. C. (1997) From outer to inner space: Linguistic categories and non-linguistic thinking. In J. Juytes \& E. Pederson (eds.), Language and conceptualization, pp.1345. Cambridge: Cambridge University Press.

Lucy, J. A. (1992a). Language diversity and thought. A reformulation of the linguistic relativity hypotheses. Cambridge: Cambridge University Press.

Lucy, J. A. (1992b). Grammatical categories and cognition. A case study of the linguistic relativity hypothesis. Cambridge: Cambridge University Press. 
MacWhinney, B. (2000a). The CHILDES project: Tools for analyzing talk (3rd edn., vol. 1): Transcription format and programs. Mahwah, NJ: Erlbaum.

MacWhinney, B. (2000b). The CHILDES project: Tools for analyzing talk (3rd edn., vol. 2): The database. Mahwah, NJ: Erlbaum.

McLaughlin, B. (1978). Second language acquisition in childhood. Hillsdale, NJ: Lawrence Erlbaum.

Meisel, J. (2000). Early differentiation of languages in bilingual children. In Li Wei (ed.), The bilingualism reader, pp. 344369. London: Routledge.

Mougeon, R., Nadasdi, T., \& Rehner, K. (2005) Contact-induced linguistic innovations on the continuum of language use: The case of French in Ontario. Bilingualism, Language and Cognition, 8 (2), 99-115.

Muthman, G. (1991). Rückläufiges deutsches Wörterbuch. Tübingen: Niemeyer.

Naigles, R. L, Eisenberg, A. R, Kako, E. T, Highter, M., \& McGraw, N. (1998). Speaking of motion: Verb use in English and Spanish. Language and Cognitive Processes, 13 (5), 521-549.

Odlin, T. (2005). Cross-linguistic influence. In C. J. Doughty \& M. H. Long (eds.), The handbook of second language acquisition, pp. 436-486. Oxford: Blackwell.

Odlin, T. (2008). Conceptual transfer and meaning extension. In P. Robinson \& N. Ellis (eds.), Handbook of cognitive linguistics and second language acquisition, pp. 306-350. Oxon and New York: Routledge.

Özçalışkan, Ş., \& Slobin, D. I. (2000). Climb up vs. ascend climbing: Lexicalization choices in expressing motion events with manner and path components. In S. CatherineHowell, S. A. Fish \& T. K. Lucas (eds.), Proceedings of the 24th Annual Boston University Conference on Language Development (vol. 2), pp. 558-570. Somerville, MA: Cascadilla Press.

Pawley, A., \& Syder, F. (2000). The one-clause-at-a-time hypothesis. In H. Riggenbach, (ed.), Perspectives on fluency, pp. 163-199. Ann Arbor: University of Michigan Press.

Plauen, E. O. (1996 [1952]) Vater und Sohn (vol. 2). Ravensburger Taschenbuchverlag.

Ringbom, H. (1987). The role of the first language on foreign language learning. Clevedon: Multilingual Matters.

Ringbom, H. (2001). Lexical transfer in L3 production. In J. Cenoz, B. Hufeisen \& U. Jessner (eds.), Cross-linguistic influence in third language acquisition: Psycholinguistic perspectives, pp. 59-68. Clevedon: Multilingual Matters.

Schoenthal, G. (1993). Feldgliederung. In H. Glück (ed.), Metzler Lexikon Sprache, pp. 183-184. Metzler Verlag.

Sebastián, E., \& Slobin, D. I. (1994) The development of linguistic forms: Spanish. In R. Berman \& D. I. Slobin (eds.), Relating events in narratives: A developmental cross-linguistic study, pp. 239-284. Hillsdale, NJ: Erlbaum.

Slobin, D. I. (1987). Thinking for speaking. Proceedings of the Thirteenth Annual Meeting of the Berkeley Linguistics Society, pp. 435-444.

Slobin, D. I. (1996). From "thought and language" to "thinking to speaking”. In J. J. Gumperz \& S. C. Levinson (eds.), Rethinking linguistic relativity, pp. 70-96. Cambridge: Cambridge University Press.
Slobin, D. I. (2003). Language and thought online: Cognitive consequence of linguistic relativity. In D. Gentner \& S. Goldin-Meadow (eds.), Language in mind: Advances in the study of language and thought, pp. 157-192. Cambridge, MA: MIT Press.

Slobin, D. I. (2004). The many ways to search for a frog: Linguistic typology and the expression of motion events. In S. Strömqvist \& L. Verhoeven (eds.), Relating events in narrative (vol. 2): Typological and contextual perspectives, pp. 219-257. Mahwah, NJ: Lawrence Erlbaum Associates.

Slobin, D. I. (2005). Linguistic representation in motion events: What is signifier and what is signified. In C. Maeder, O. Fisher \& W. Herlofsky (eds), Iconicity inside out: Iconicity in language and literature 4, pp. 307-322. Amsterdam/ Philadelphia: John Benjamins.

Slobin, D. I. (2006). What makes manner of motion salient? Explorations in linguistic typology, discourse, and cognition. In M. Hickmann, \& S. Robert (eds.), Space in languages: Linguistic systems and cognitive categories, pp. 59-81. Amsterdam/Philadelphia: John Benjamins.

Slobin, D. I., \& Hoiting, N. (1994). Reference to movement in spoken and signed languages: Typological considerations. Proceedings of the Twentieth Annual Meeting of the Berkeley Linguistics Society, 487-505.

Talmy, L. (1985). Lexicalization patterns: Semantic structure in lexical forms. In T. Shopen (ed.), Grammatical categories and the lexicon. Volume III of Language typology and syntactic description, pp. 57-149. Cambridge: Cambridge University Press.

Talmy, L. (1991). Path realization: A typology of event conflation. Proceedings of the Seventeenth Annual Meeting of the Berkeley Linguistics Society, pp. 480-519.

Talmy, L. (2000a). Toward a cognitive semantics (vol. I): Toward a cognitive semantics: Concepts structuring systems. Cambridge, MA: MIT Press.

Talmy, L. (2000b). Toward a cognitive semantics (vol. II): Toward a cognitive semantics: Typology and process in concept structuring. Cambridge MA: MIT Press.

Tezcan, N. (1988). Elementarwortschatz Türkisch-Deutsch. Wiesbaden: Harrassowitz.

Treffers-Daller, J. (2009). Code-switching and transfer: An exploration of similarities and differences. In B. E. Bullock \& A. J. Toribio (eds.), The Cambridge handbook of linguistic code-switching, pp. 58-74. Cambridge: Cambridge University Press.

Treffers-Daller, J. (in press a). Operationalising and measuring language dominance. In M. H. Daller (ed.), The measurement of bilingual proficiency (International Journal of Bilingualism, special issue 2011).

Treffers-Daller, J. (in press b). Grammatical collocations and verb-particle constructions in Brussels French: A corpuslinguistic approach to transfer. To appear in International Journal of Bilingualism.

Treffers-Daller, J., \& Özsoy, A. S. (1995). Mündliche Sprachfaehigkeiten von türkisch-deutschen Bilingualen in Deutschland und in der Türkei: eine syntaktische Analyse von türkischen Bildbeschreibungen. In J. TreffersDaller \& H. Daller (eds.), Zwischen den Sprachen: Sprachgebrauch, Sprachmischung und Sprachfaehigkeiten türkischer Rückkehrer aus Deutschland (vol. 2): pp. 95122. Istanbul: The Language Center, Boğaziçi University. 
Treffers-Daller, J., Özsoy, S., \& van Hout, R. (2007). (In)complete acquisition of Turkish among TurkishGerman bilinguals in Germany and Turkey: An analysis of complex embeddings in narratives. International Journal of Bilingualism and Bilingual Education, 10 (3), 248276.

Treffers-Daller, J., \& Tidball, F. (in prep). Learnability and event construal among French learners of English and British learners of French.
Von Stutterheim, C., \& Nüse, R. (2003). Processes of conceptualisation in language production. Linguistics (Special Issue: Perspectives in language production), 41 (5), 851-881.

Von Stutterheim, C., Nüse, R., \& Murcia-Serra (2002). Crosslinguistic differences in the conceptualisation of events. In B. Behrens, C. Fabricius-Hansen \& S. Johansson (eds.), Information structure in a cross-lingustic perspective, pp. 179-198. Amsterdam: Rodopi. 